\title{
Preparation of Enamides via Palladium-Catalyzed Amidation of Enol Tosylates
}

\author{
Artis Klapars, * Kevin R. Campos, Cheng-yi Chen, and Ralph P. Volante \\ Department of Process Research, Merck Research Laboratories, P. O. Box \\ 2000, Rahway, New Jersey 07065
}

\section{${ }^{1} \mathrm{H}$ and ${ }^{13} \mathrm{C}$ NMR Spectra}




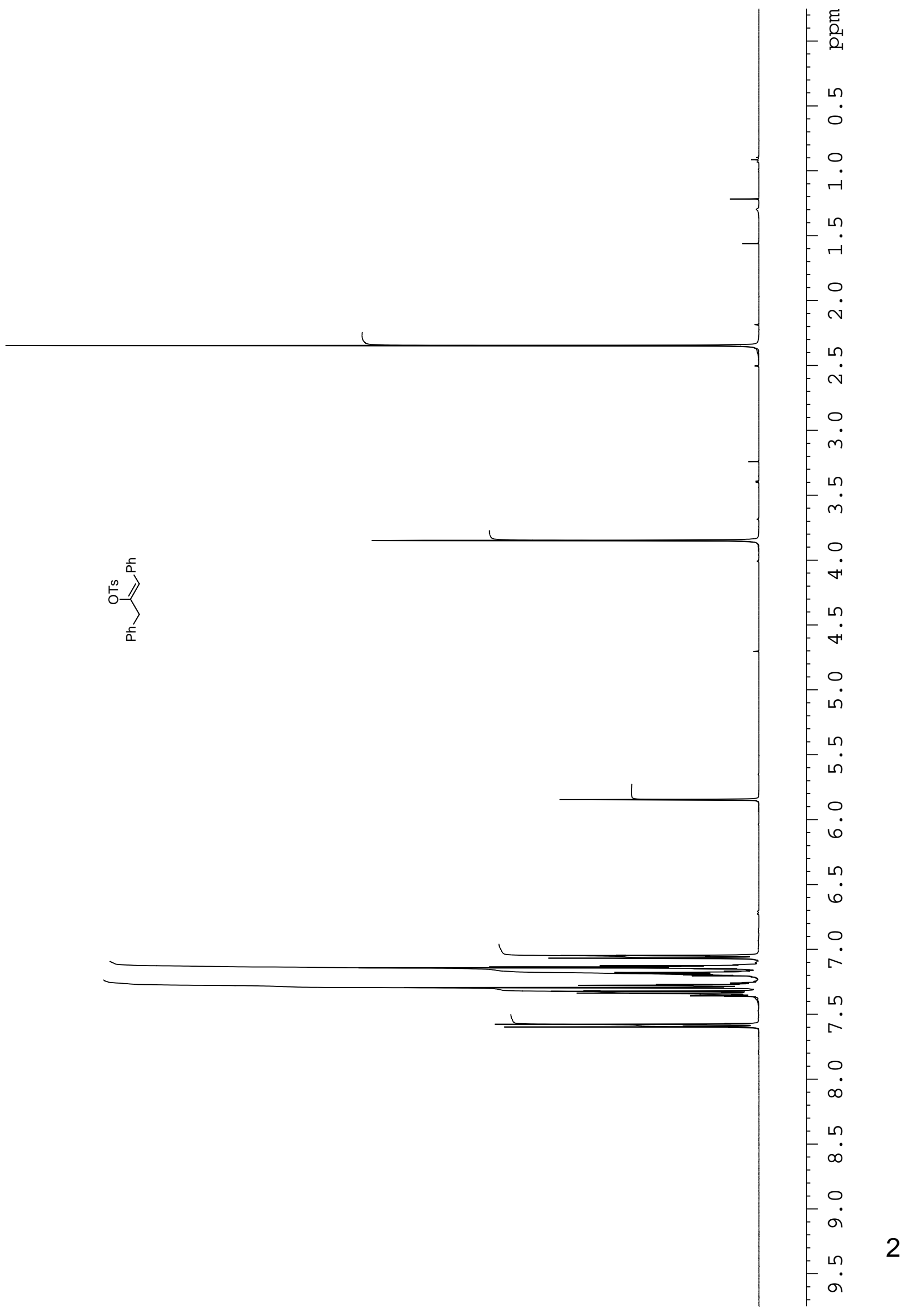



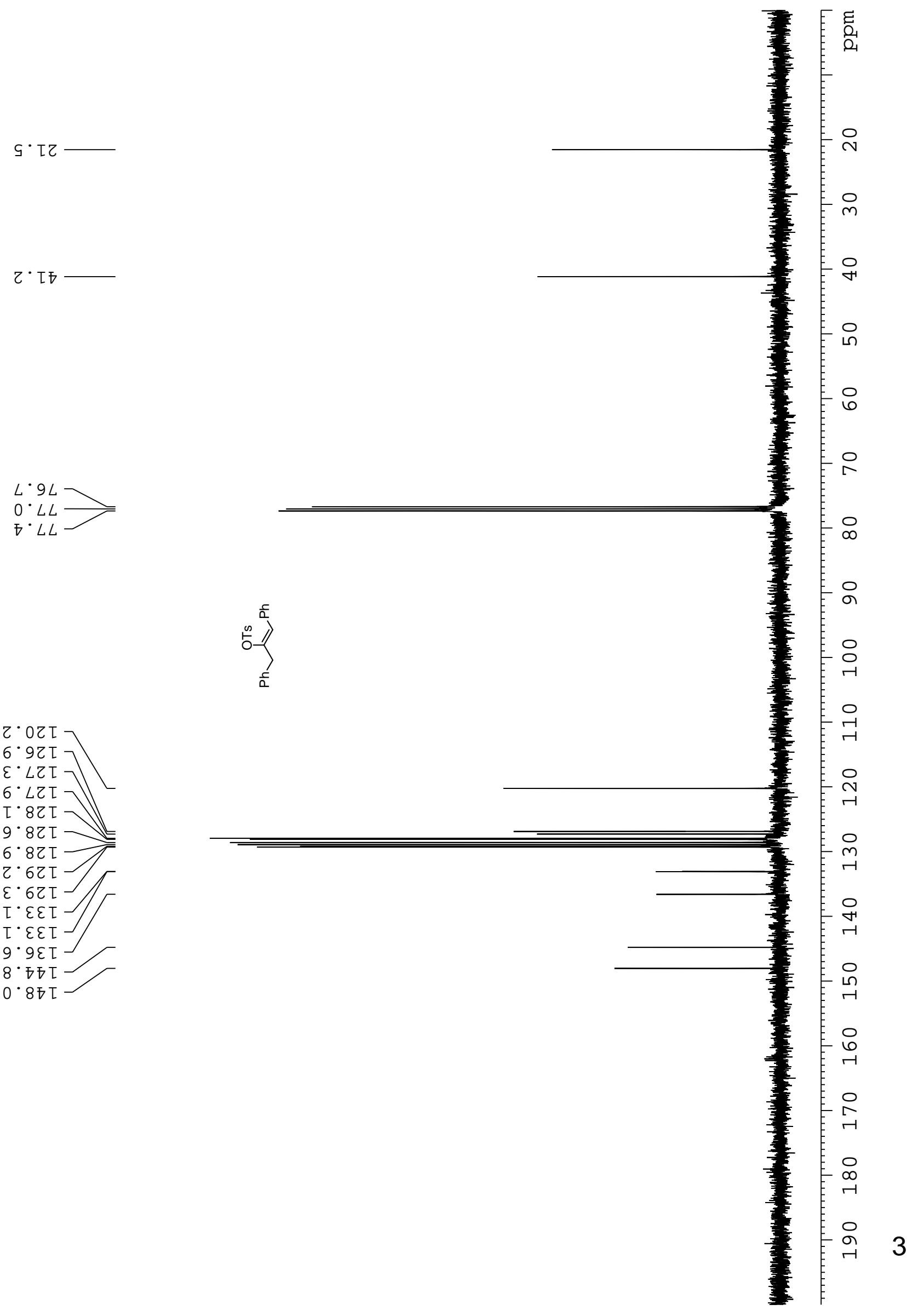


$$
{ }^{-}-4
$$




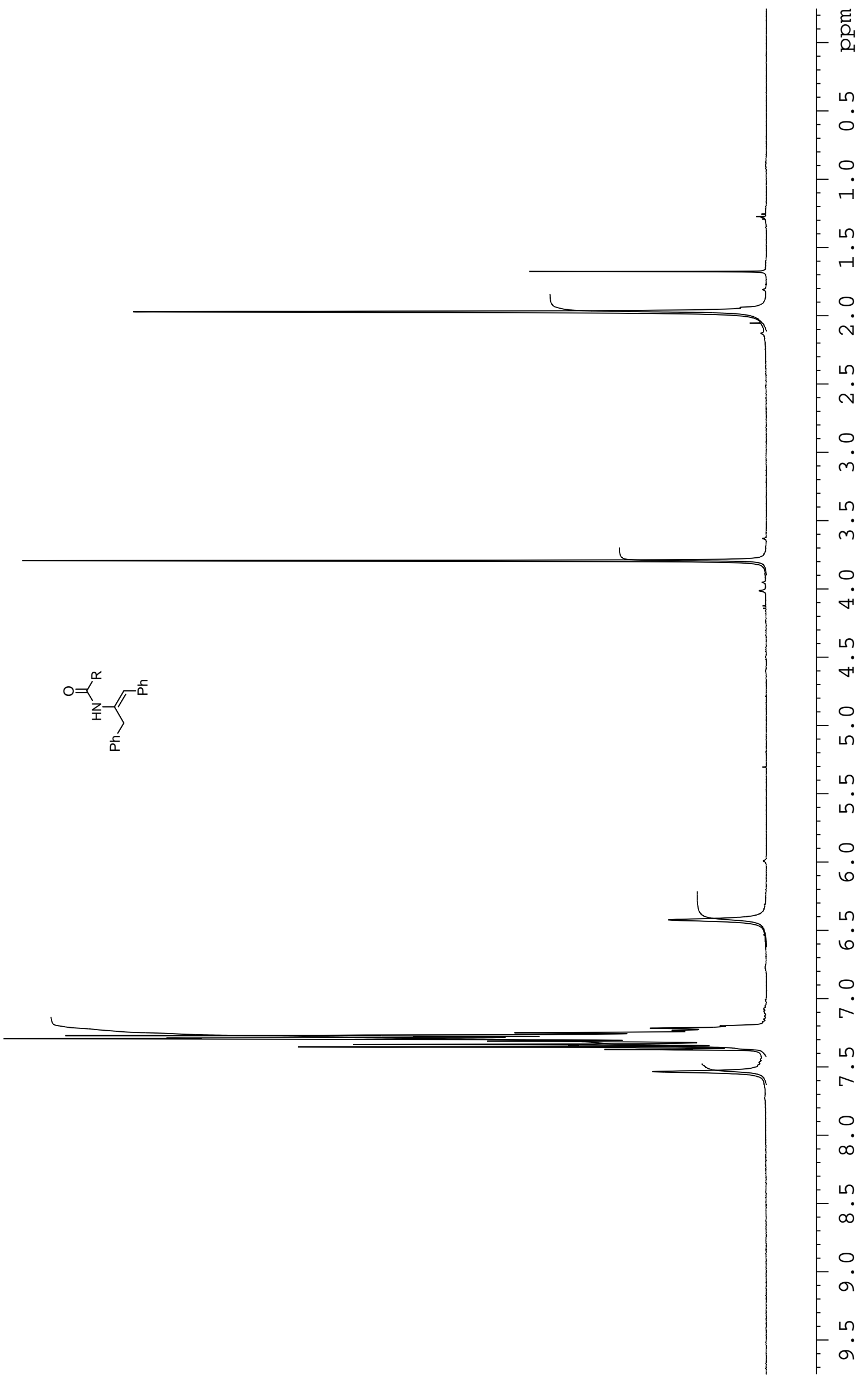




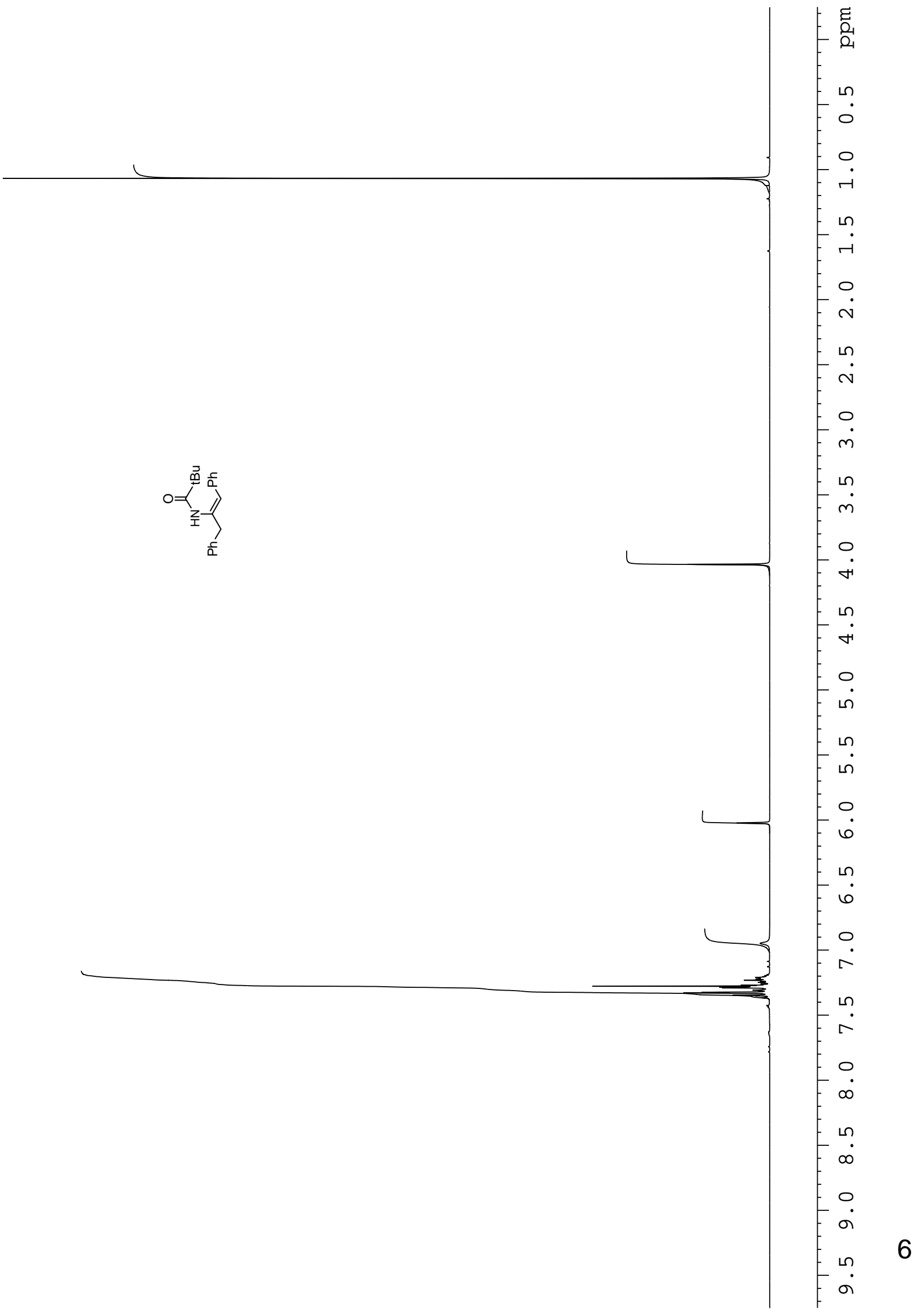


$\varepsilon \cdot L \tau$

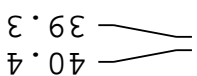

$L \cdot 9 L \square$
$0 \cdot L L \longrightarrow$
$\mathcal{E} \cdot \square L$

$\varepsilon \cdot 8 \tau \tau-$

ஏ・9Z

$0 \cdot \angle Z I$

$Z \cdot 8 Z \mathrm{I}$

$5 \cdot 8 Z \mathrm{I}$

$9 \cdot 8 Z \mathrm{I}$

乙・6乙 I

$9 \cdot \varsigma \varepsilon \mathrm{L}$

$\tau^{\circ} \angle \varepsilon T$

$L \cdot 8 \varepsilon I$

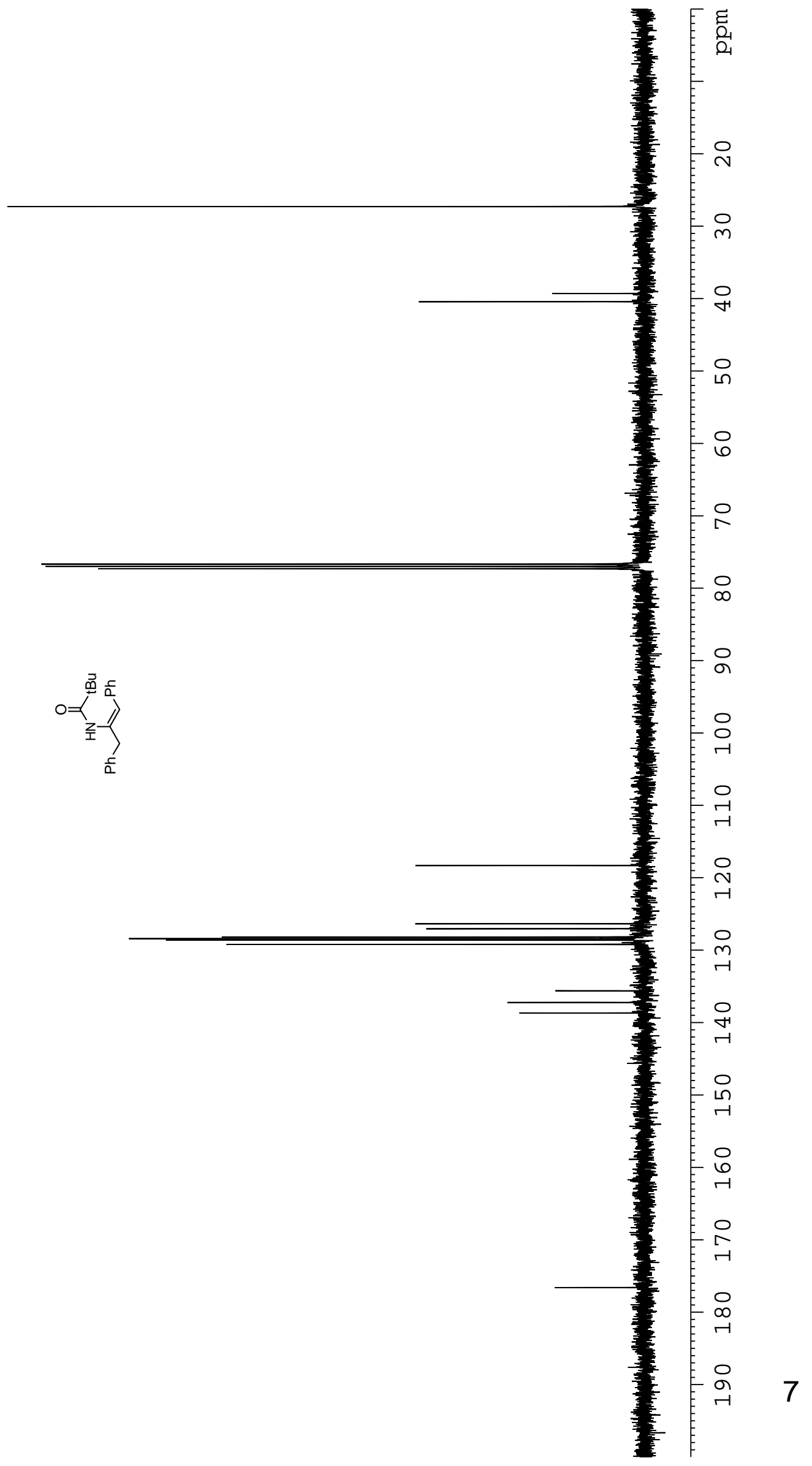




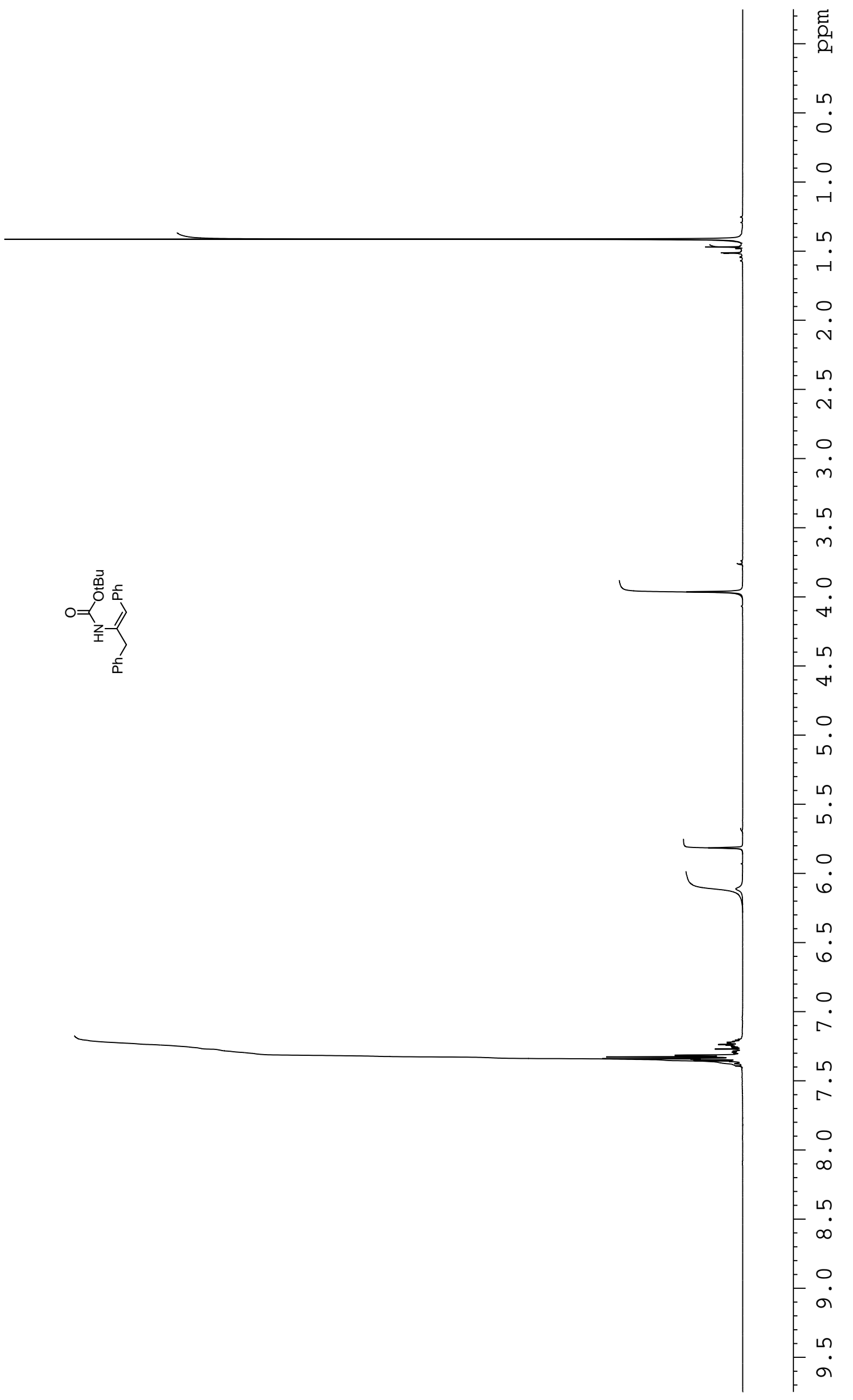




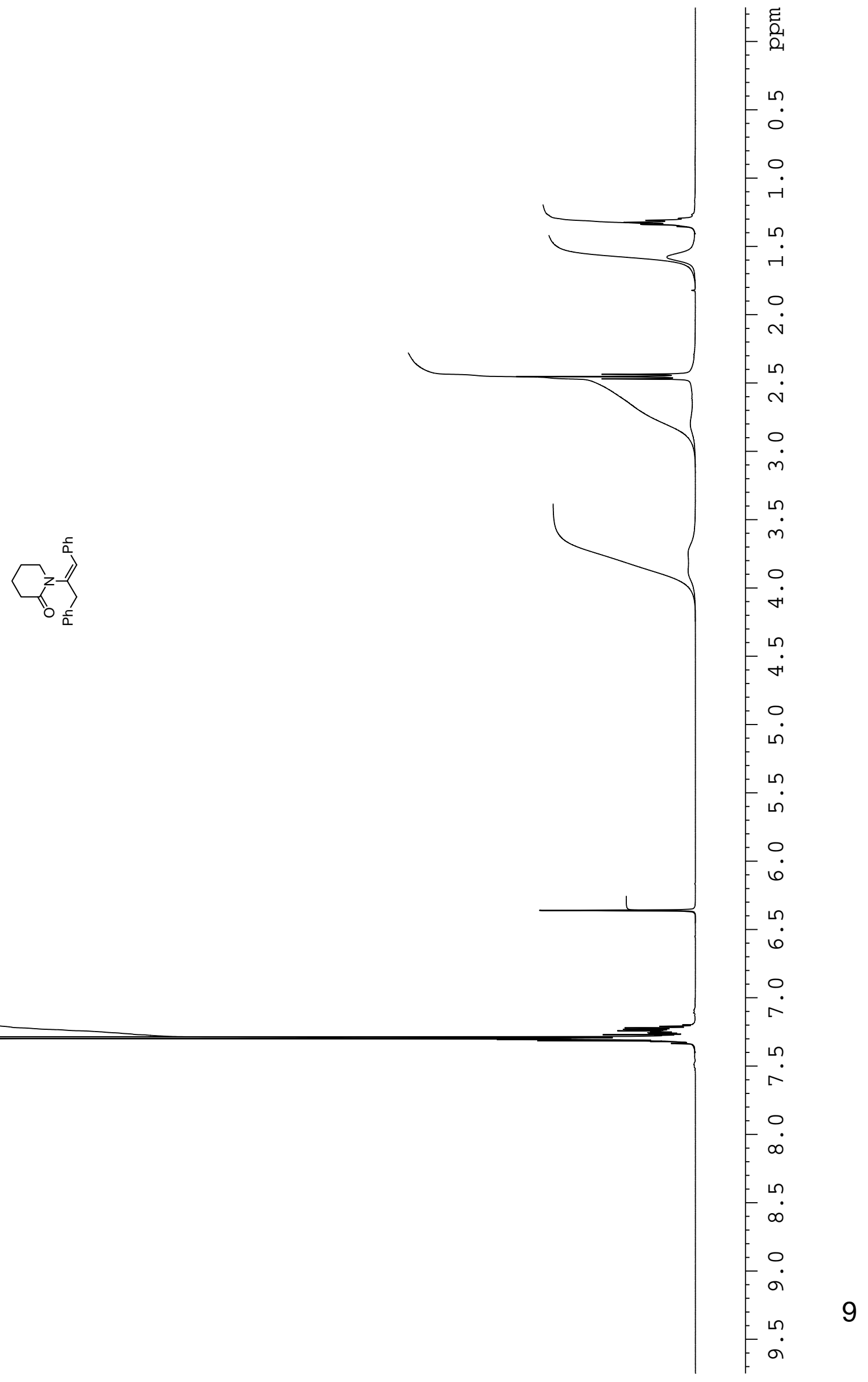


$L \cdot O Z$

$0 \cdot \varepsilon z$

$9^{\circ} \mathrm{z \varepsilon}$

$\tau \cdot \tau \hbar$

7. 67

$L \cdot 9 L \square$
$0 \cdot L L \longrightarrow$
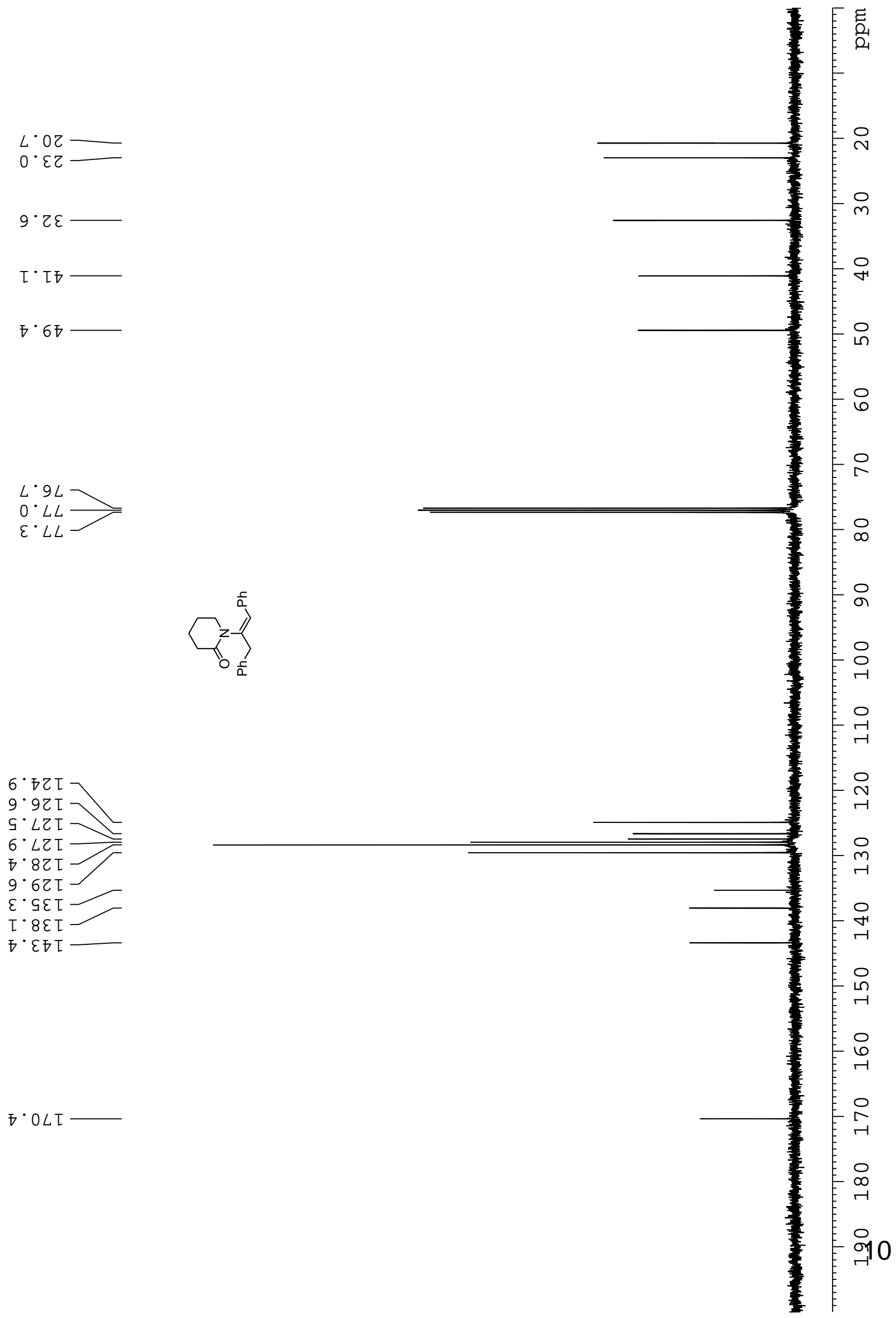


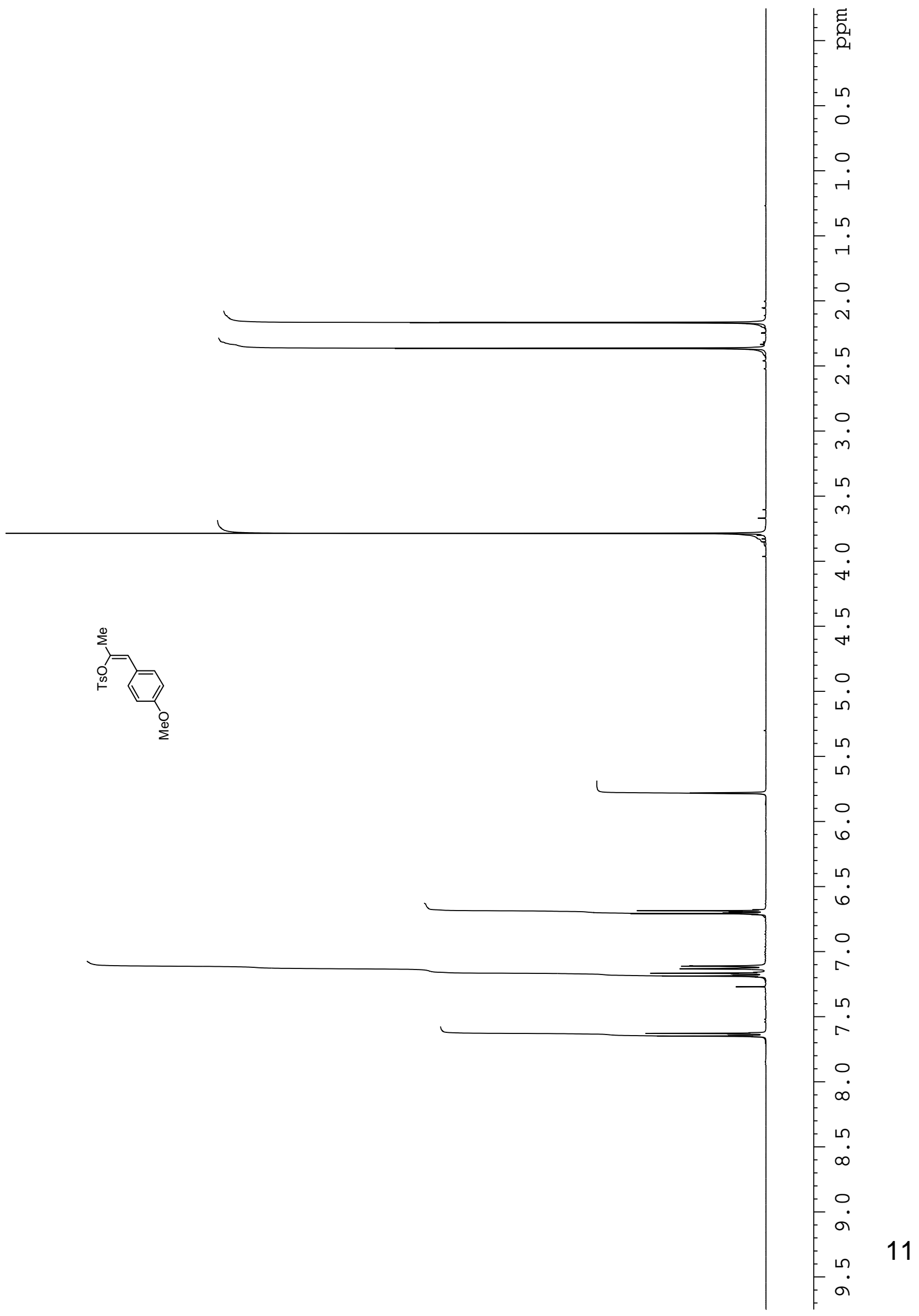




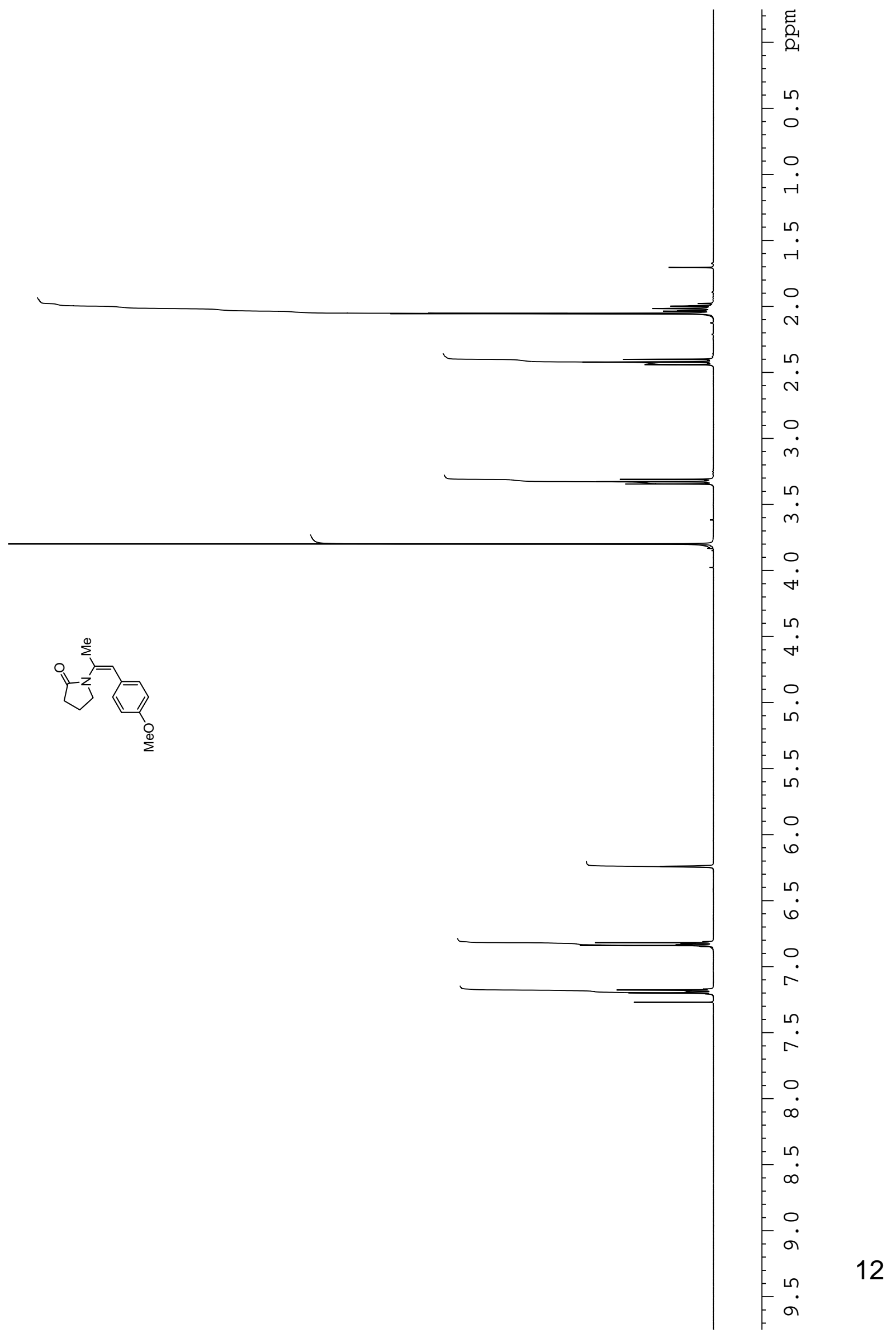




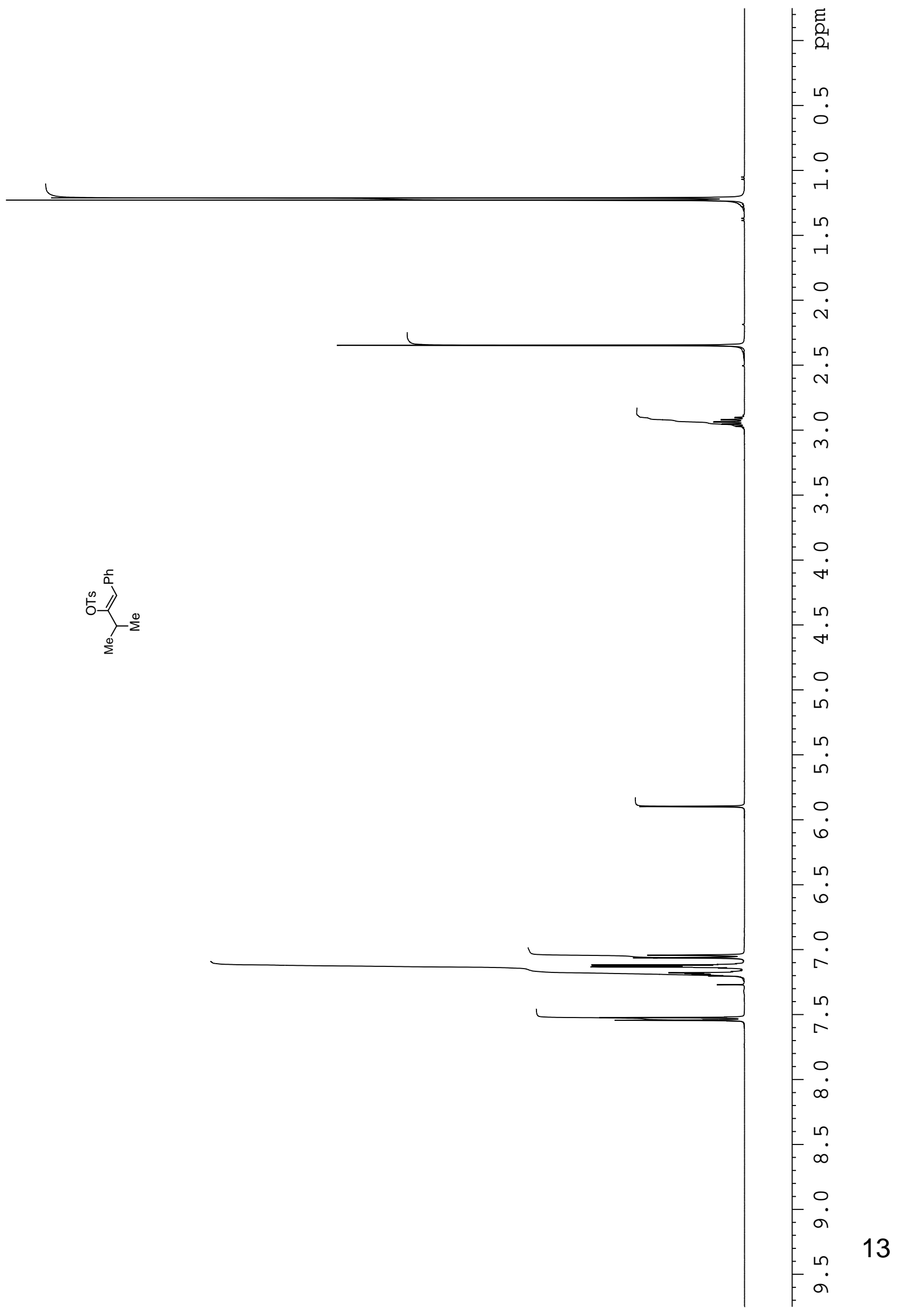




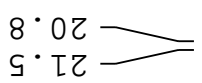

$8^{\circ} 2 \varepsilon$
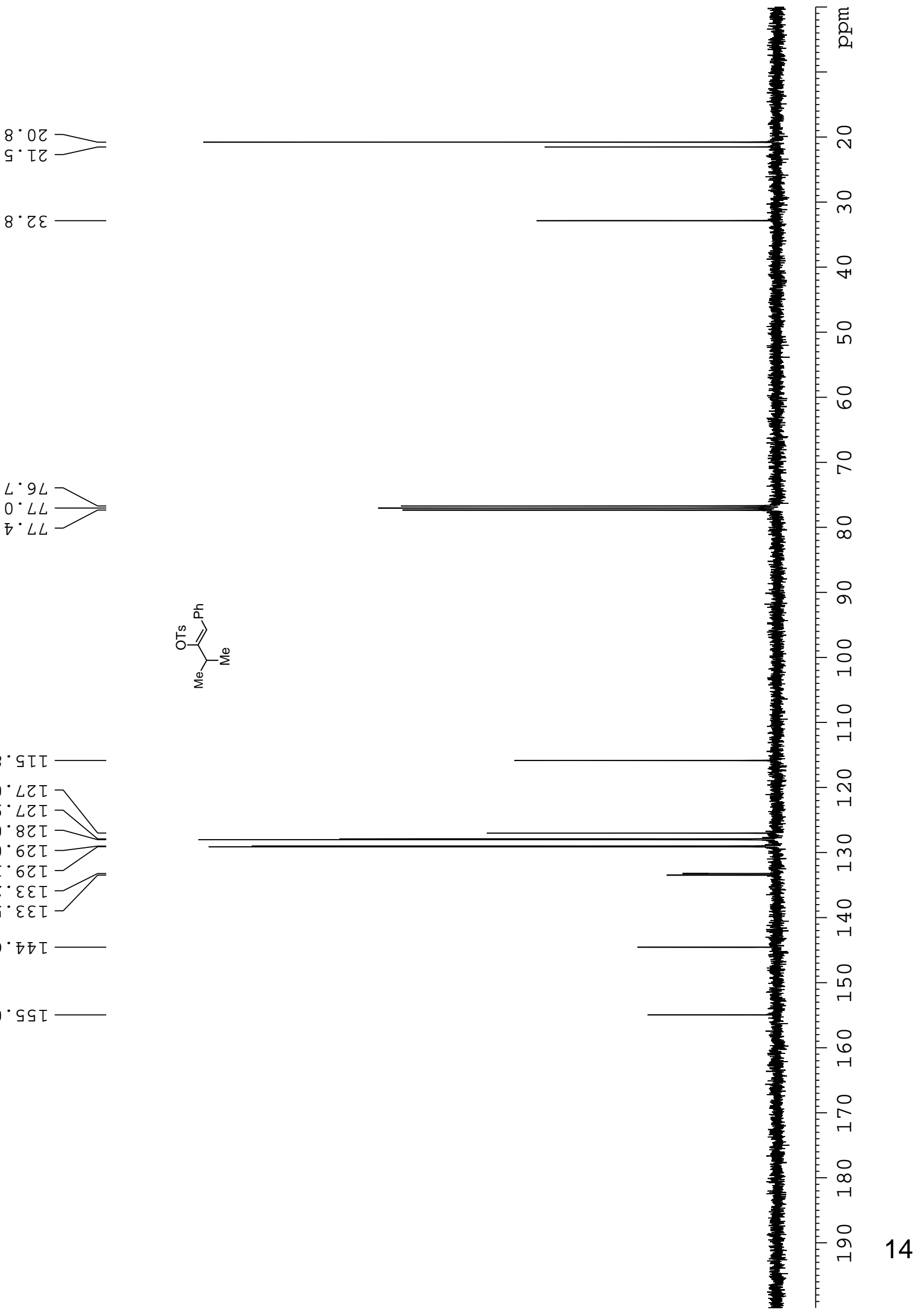


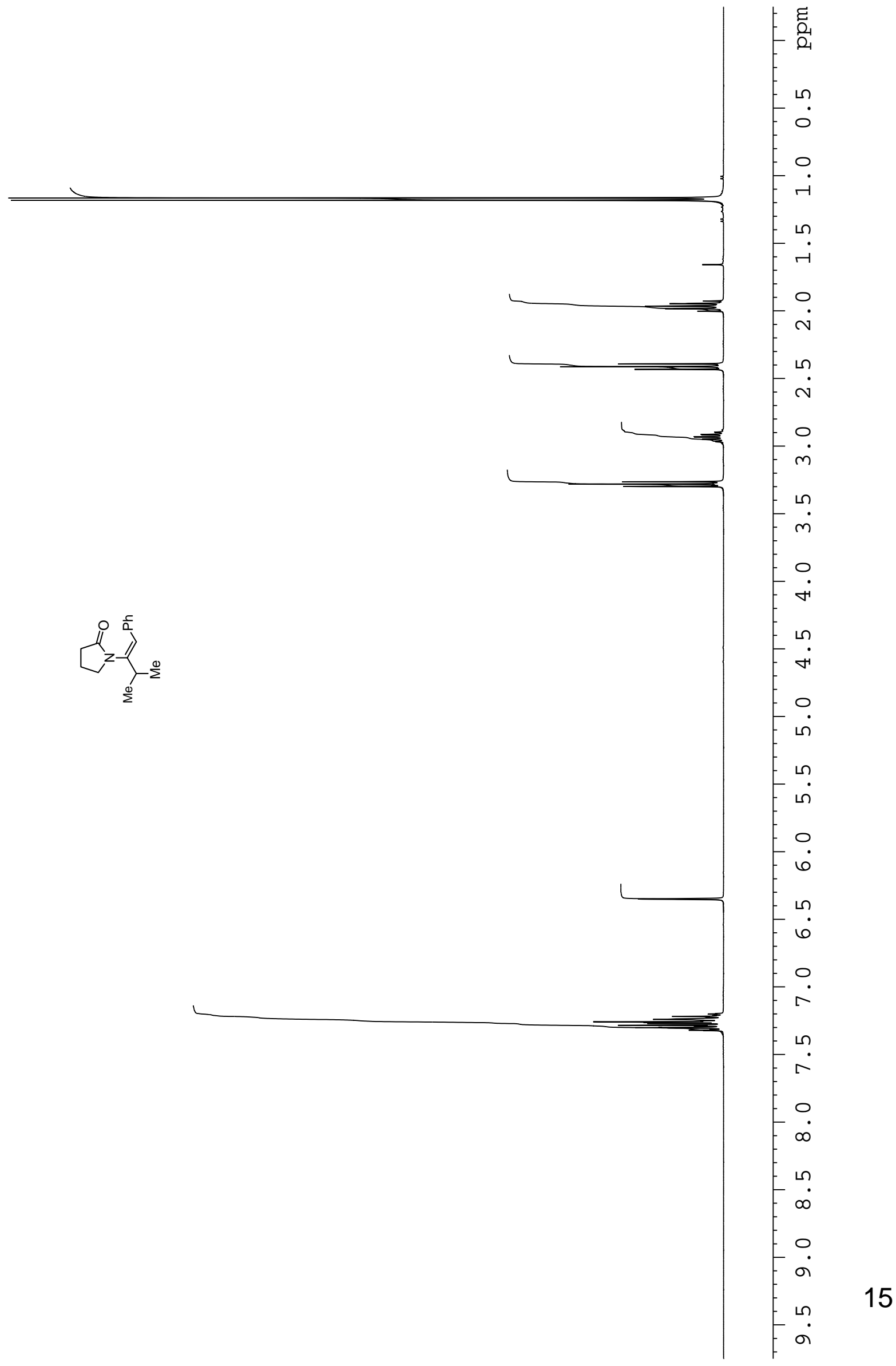


$\varepsilon \cdot 6 \tau \longrightarrow$
$L \cdot 0 \tau=$

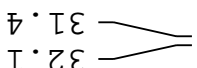

I.67

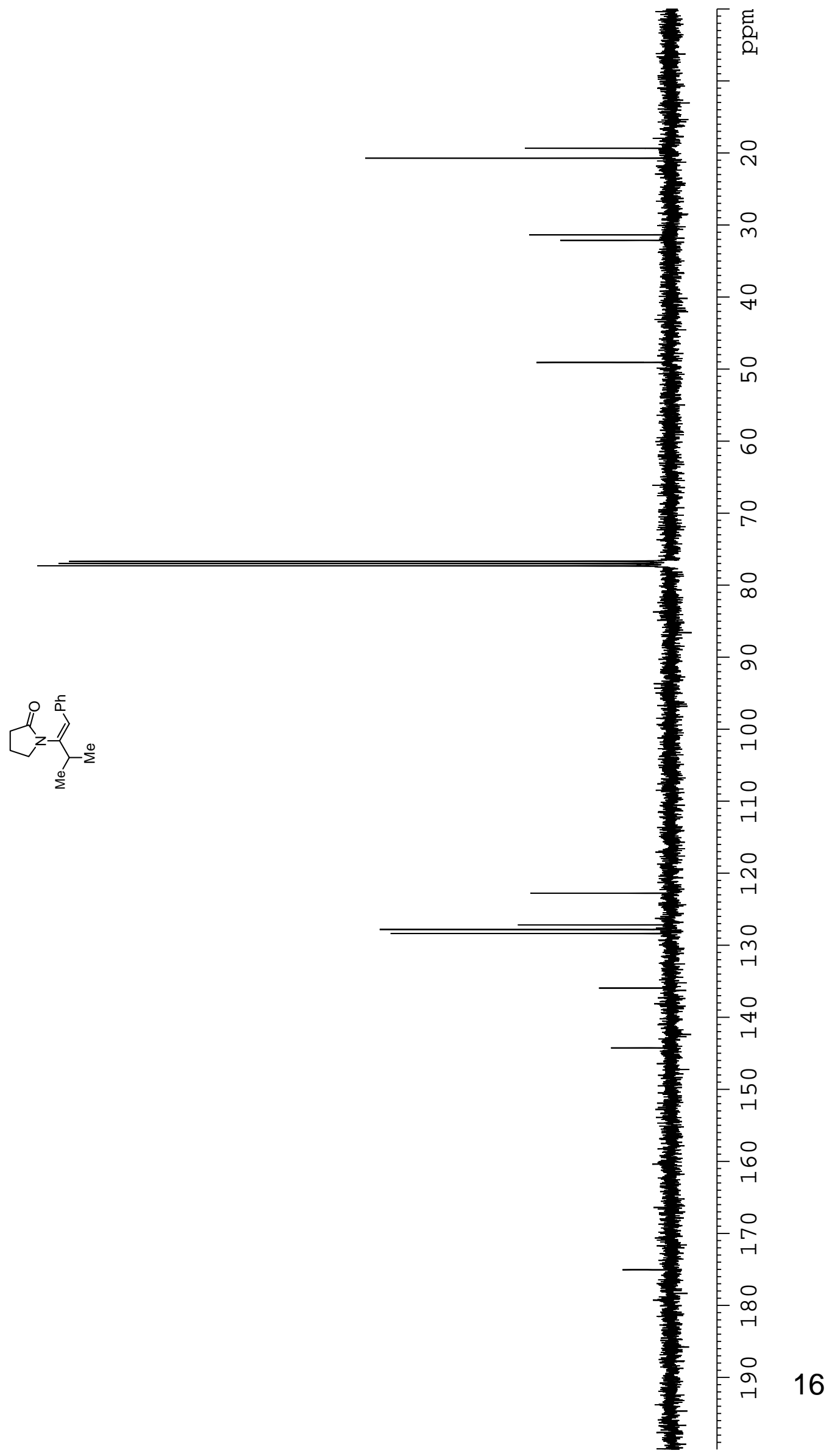

$8^{\bullet}$ てて

$Z^{\bullet} L Z I$

8. $\angle Z T$

万・8乙L

$6^{\circ} \mathrm{GEI}$

て・ウゅて

$L \cdot 9 L$
$\mathcal{O}^{*} L L$

$0 \cdot G L I$ 


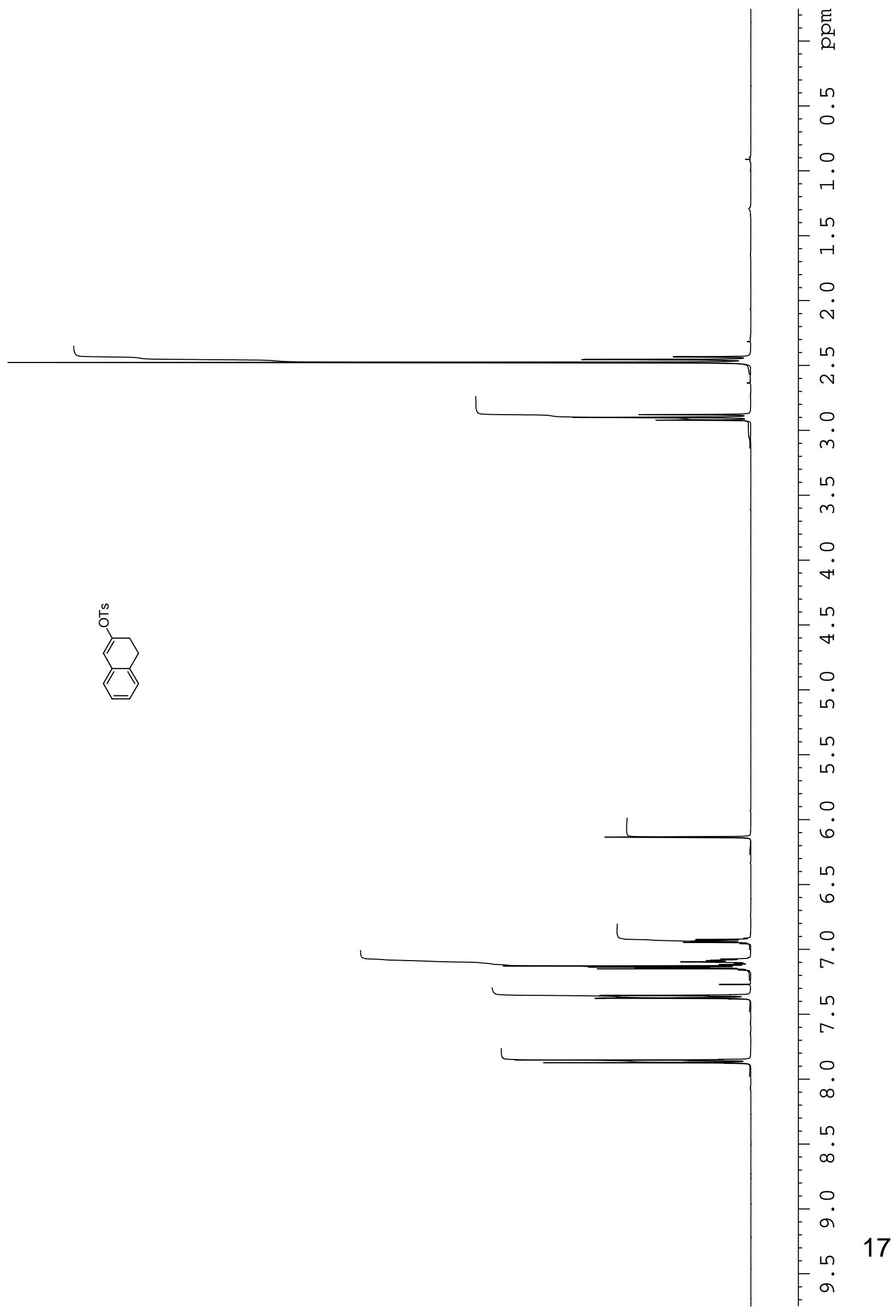



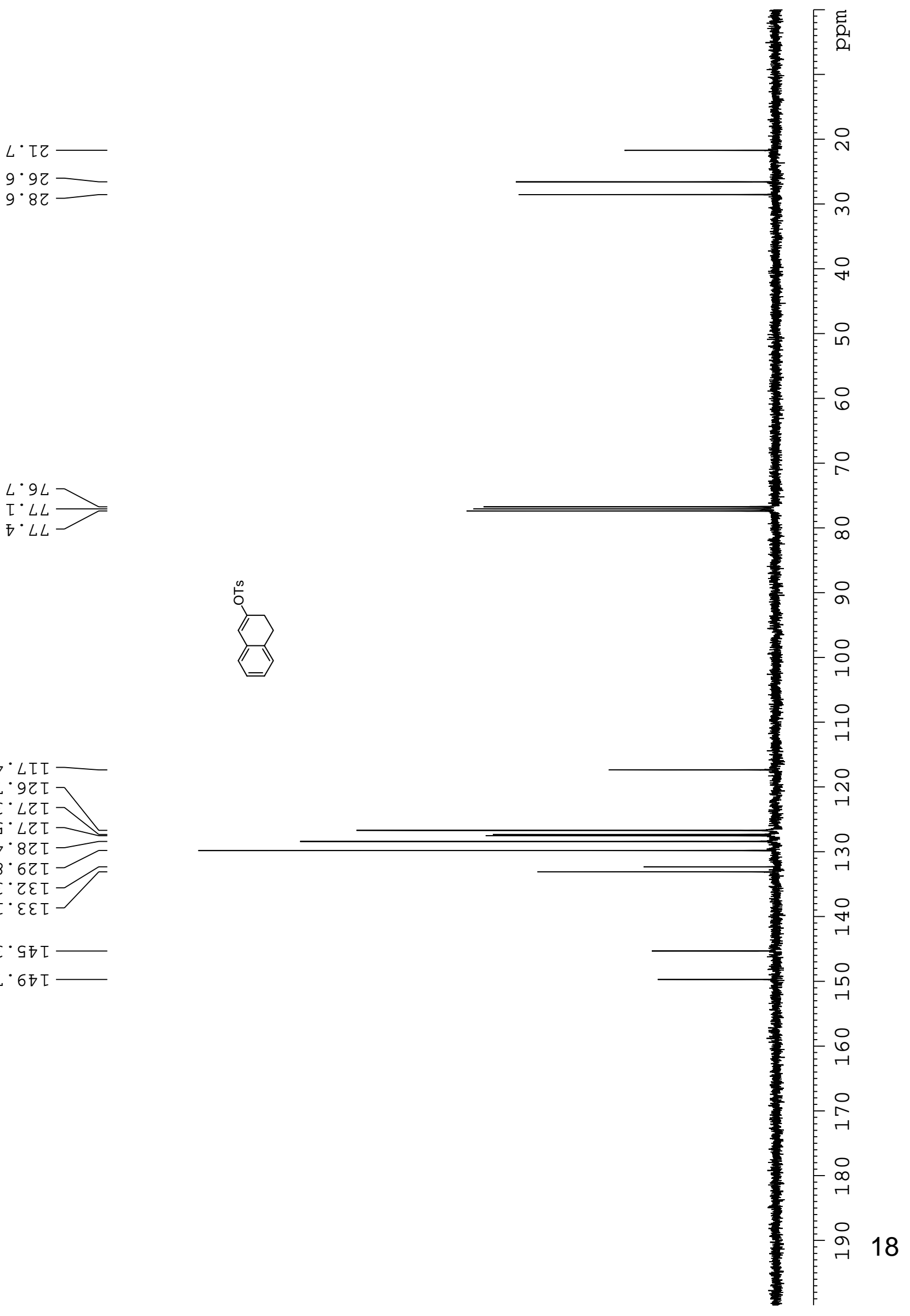


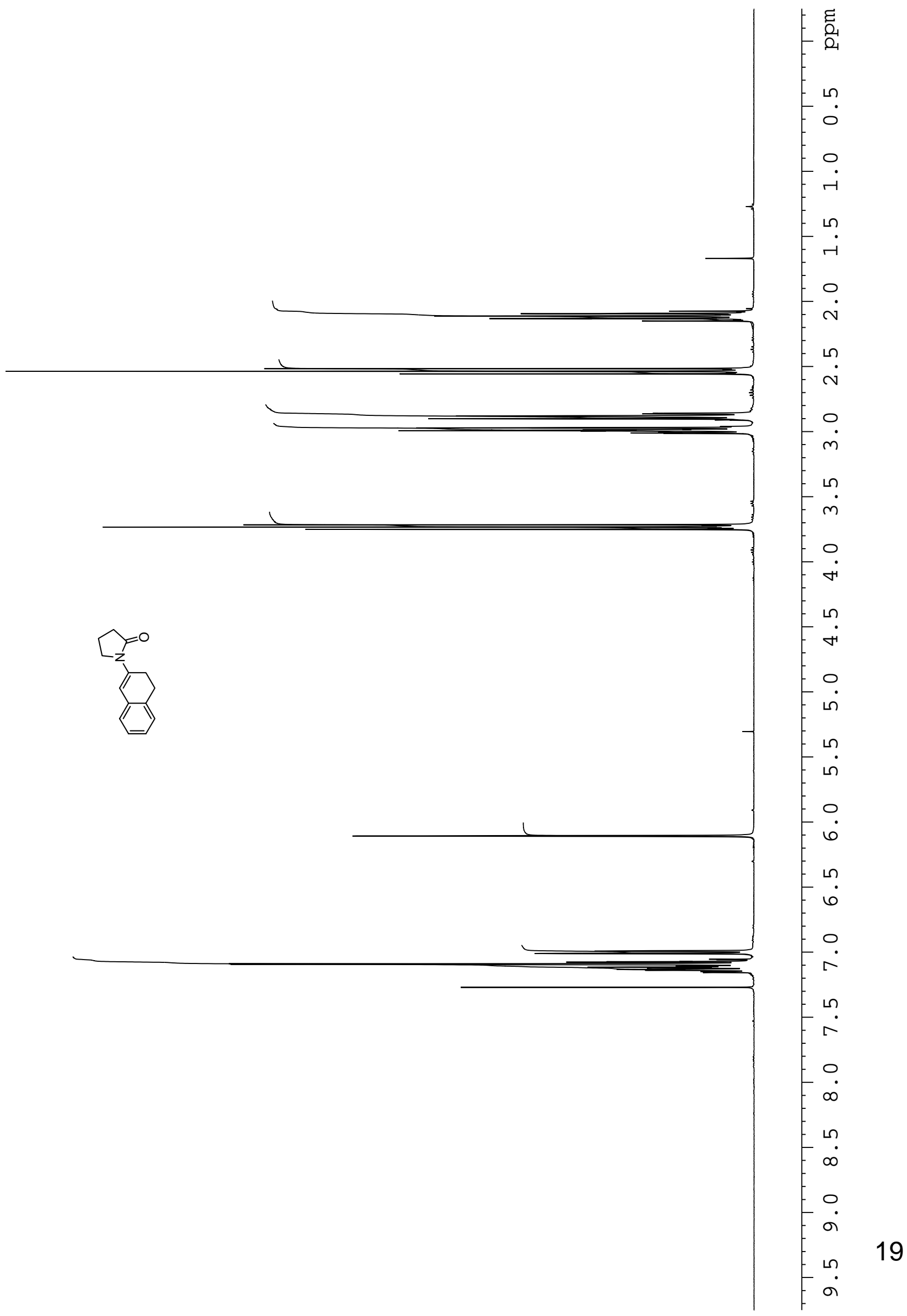



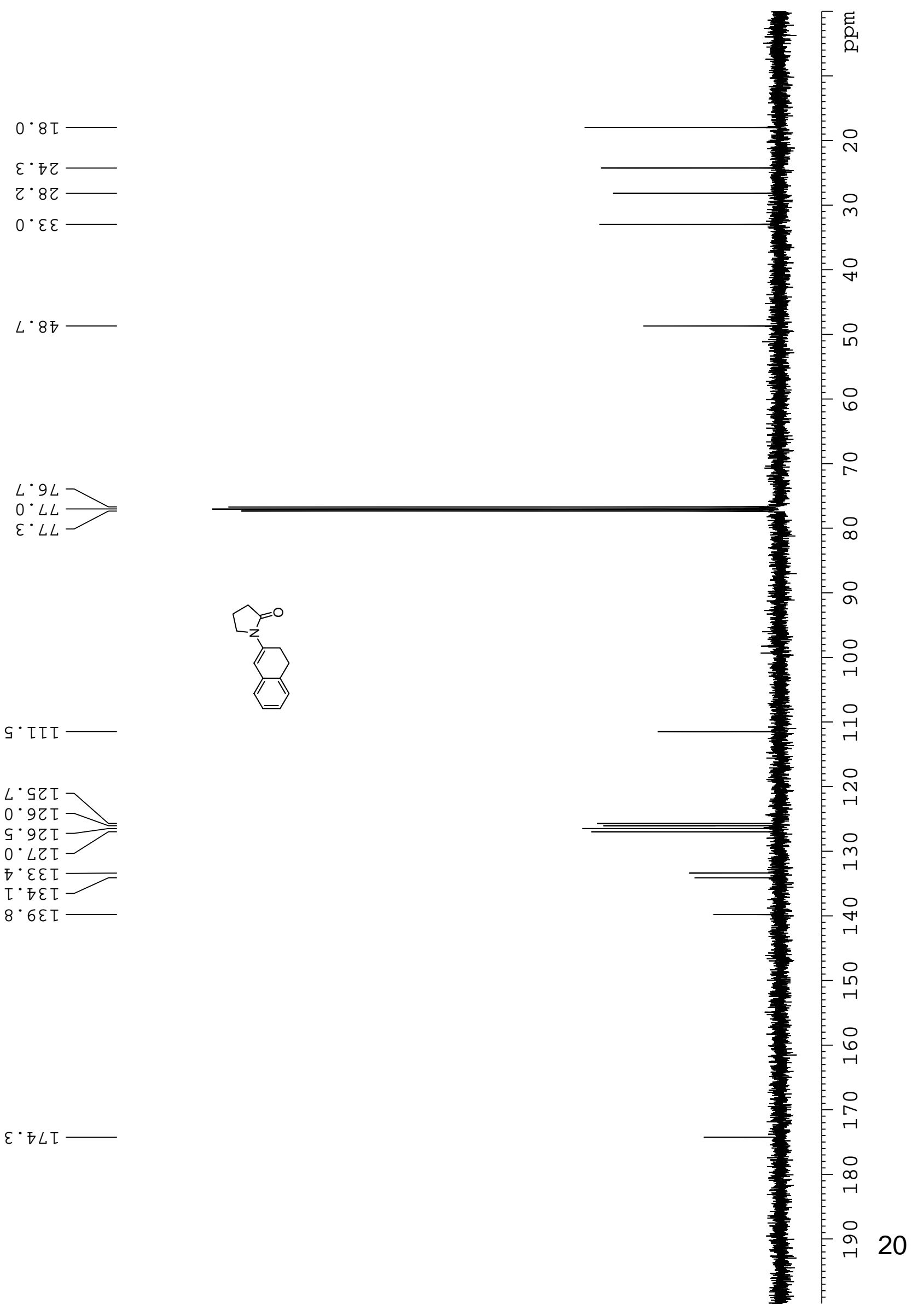


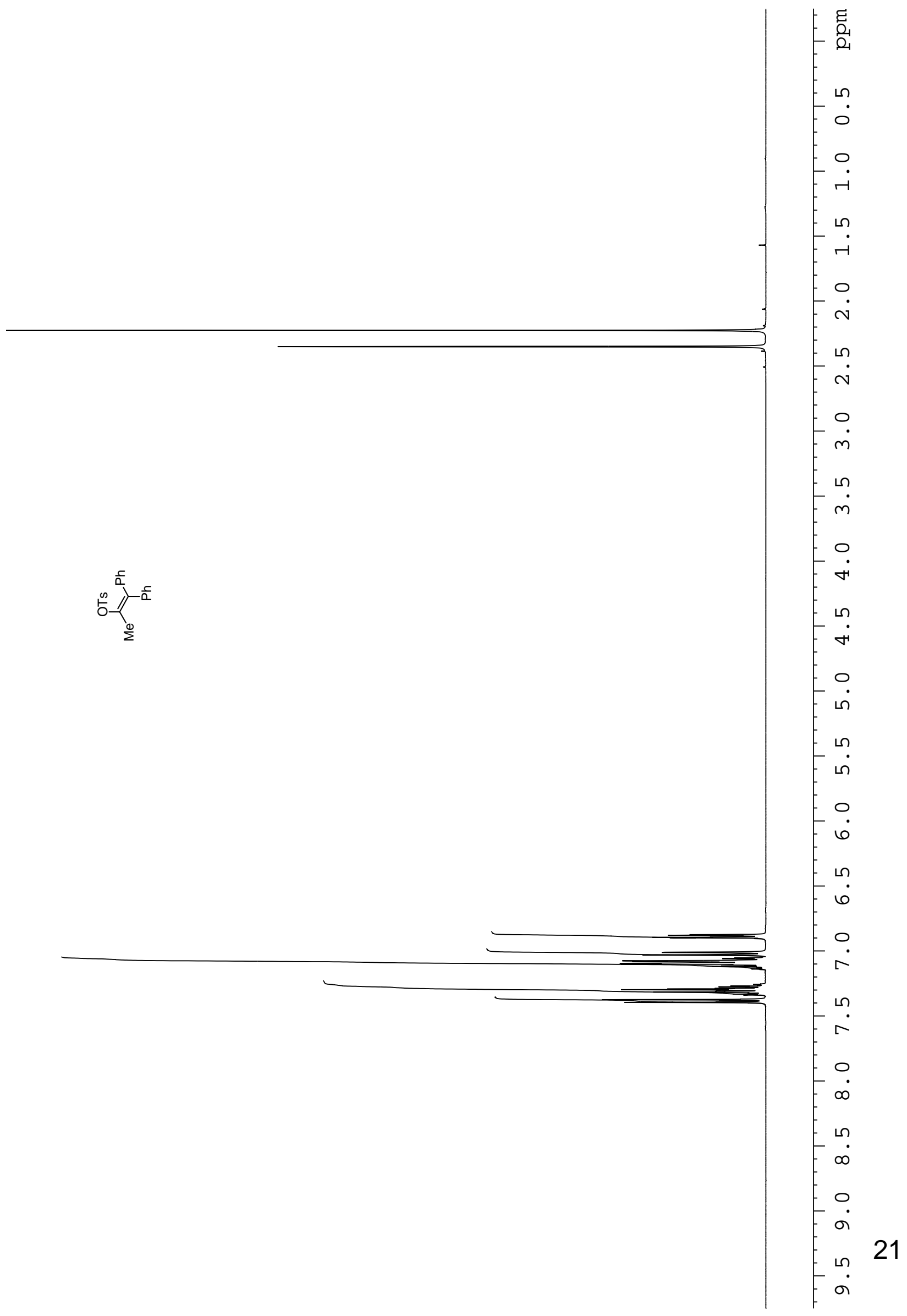



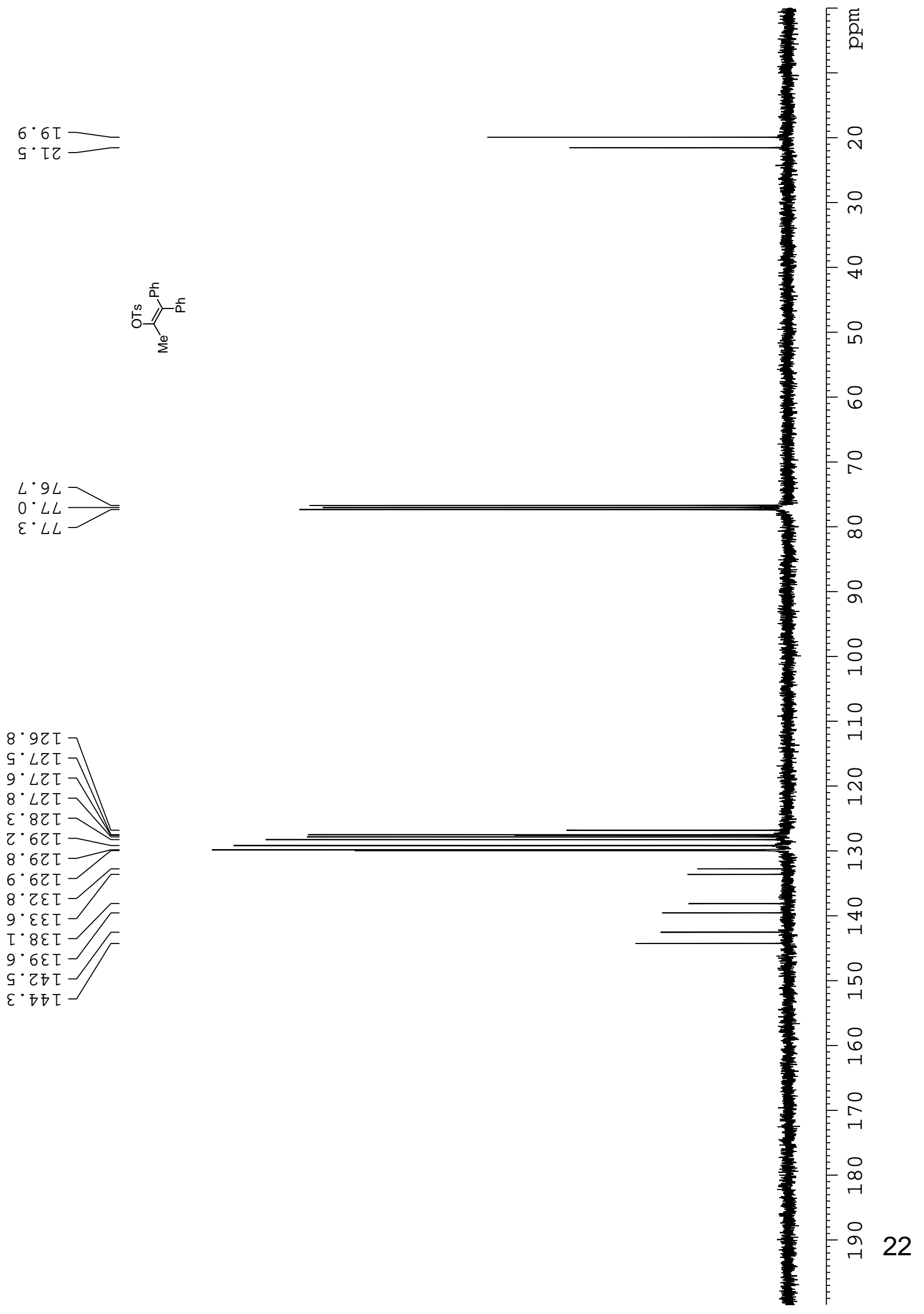


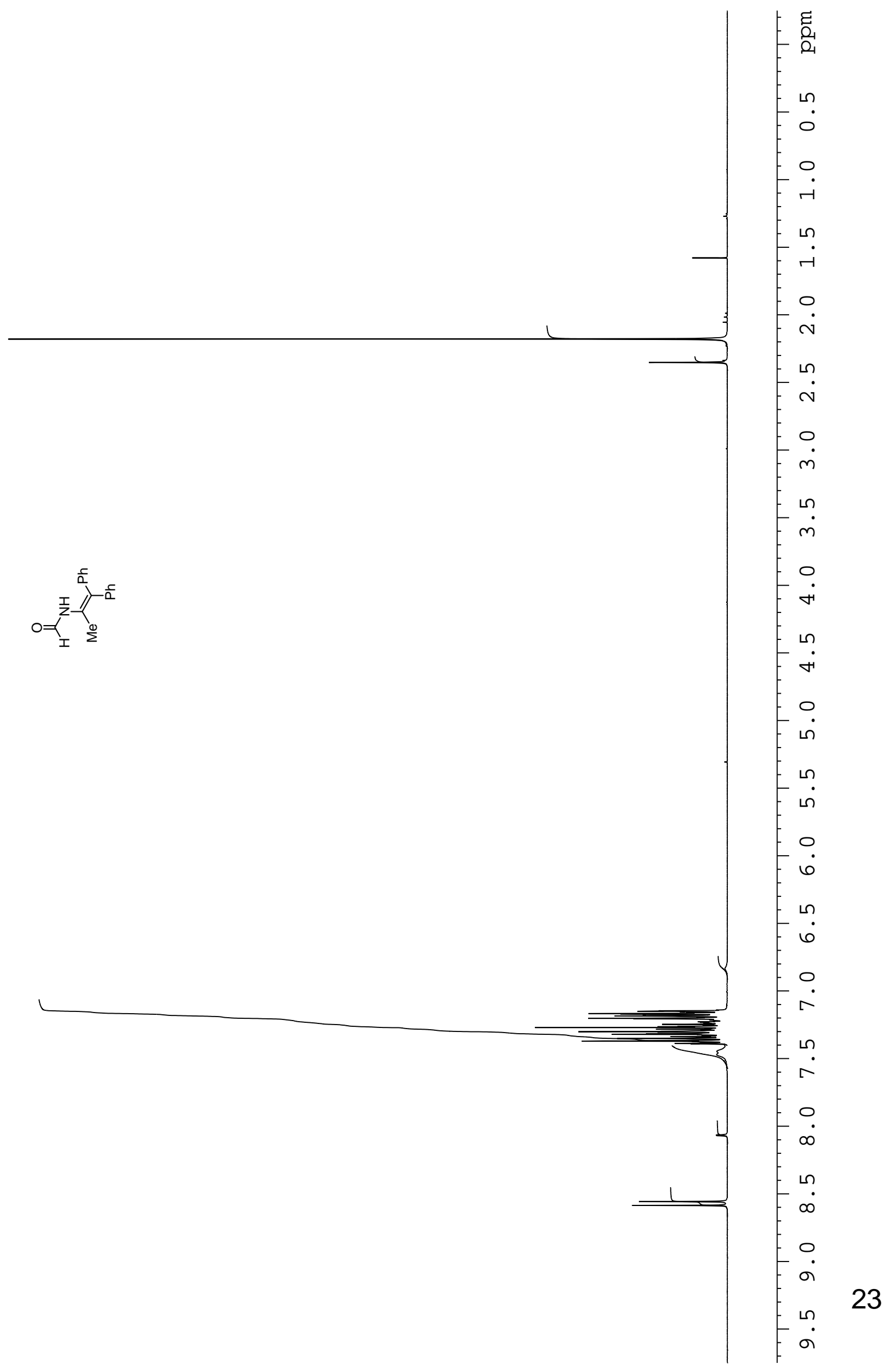


$\tau \cdot 9 \mathrm{I}$
$\mathrm{I} \cdot 8 \mathrm{I}$

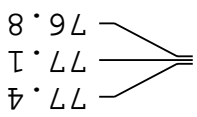

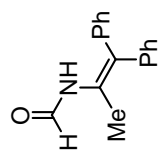
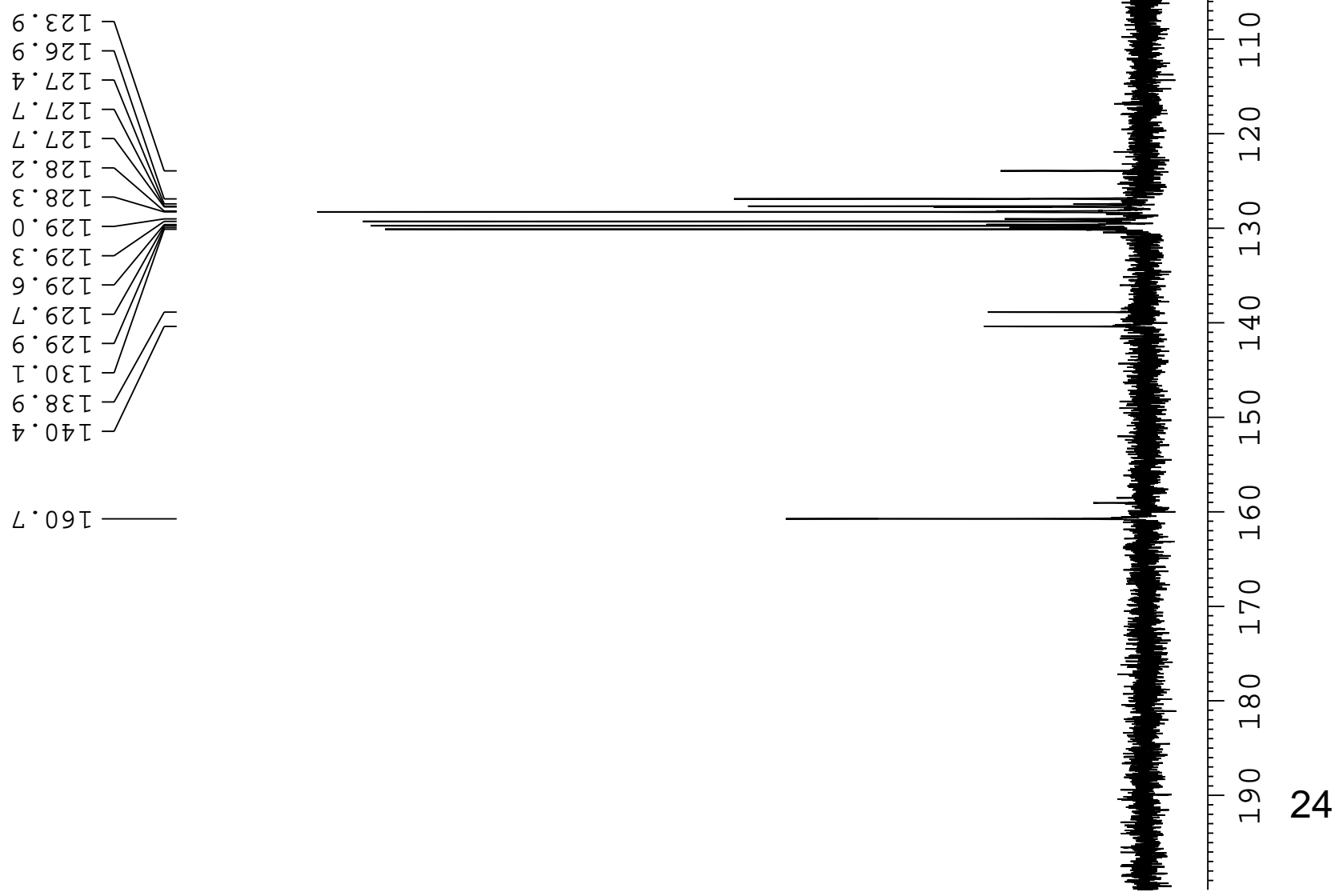


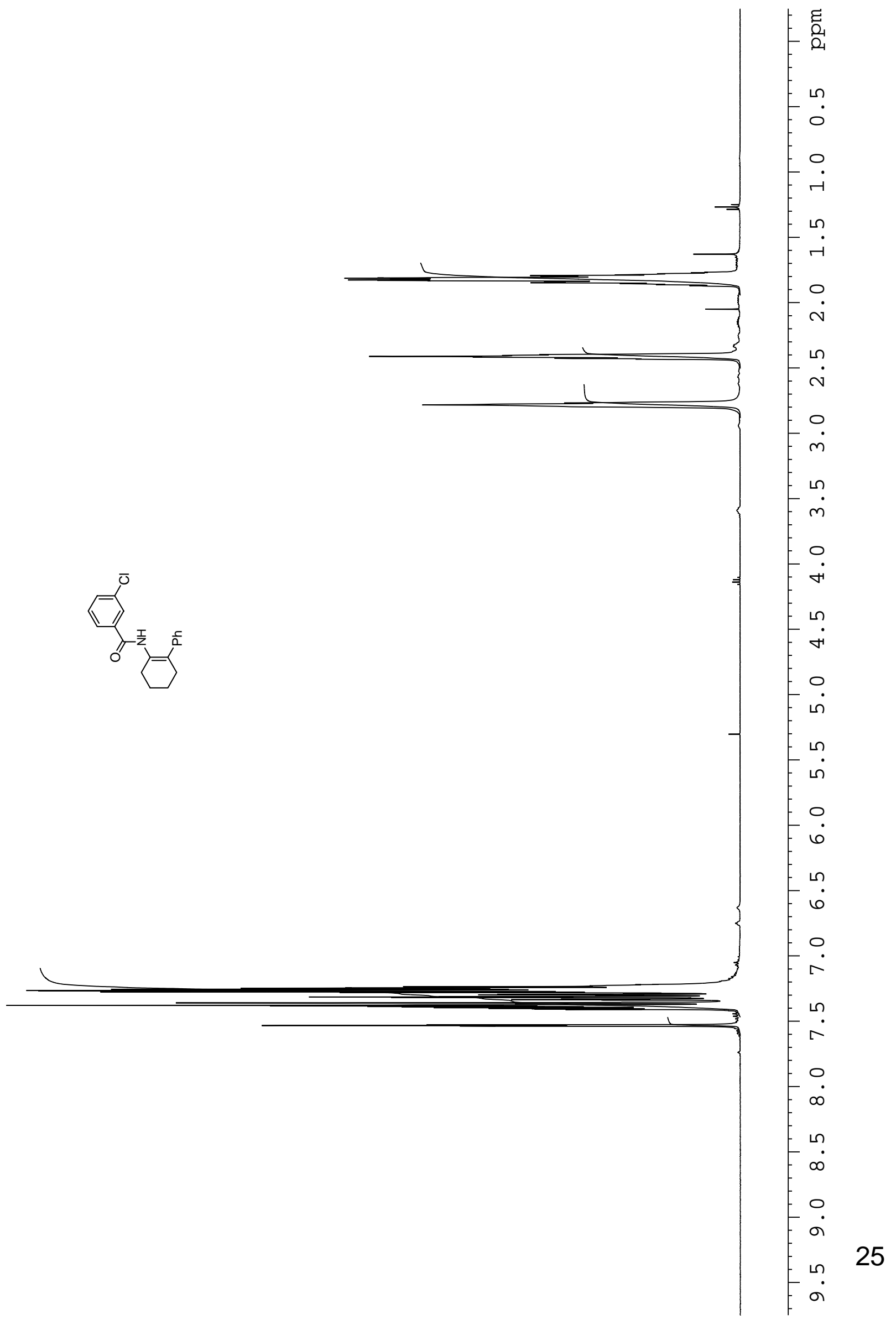




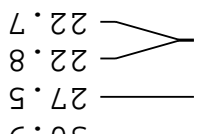

$6 \cdot 0 \varepsilon$

$L^{\cdot 9 L}$
$0 \cdot L L \longrightarrow$
$\varepsilon \cdot L L$<smiles>[CH2]C(=O)c1cccc([Hg])c1</smiles>

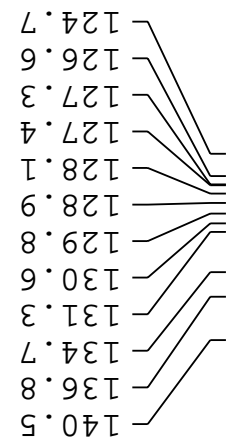

$8^{\cdot} \varepsilon 9$ I

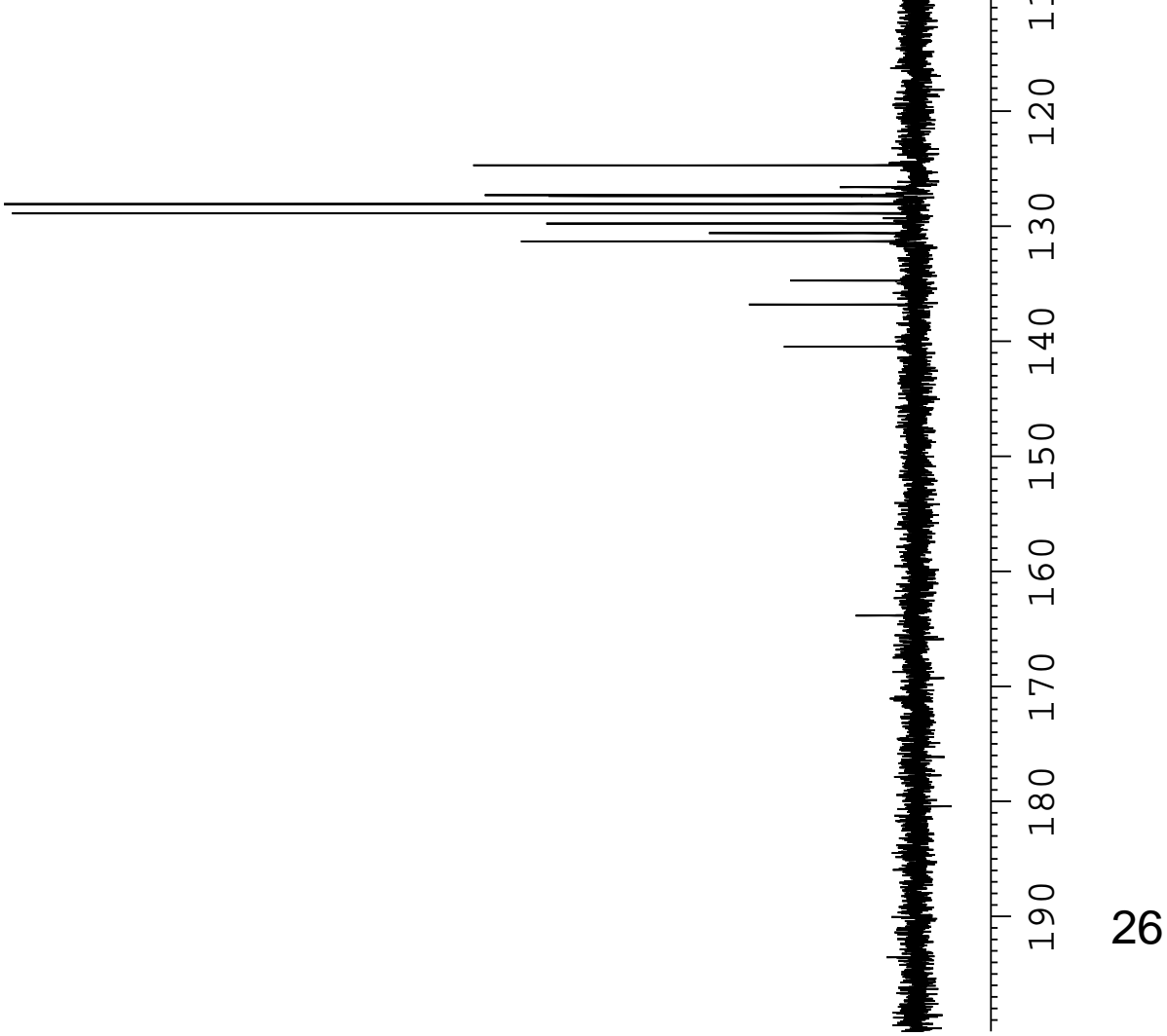




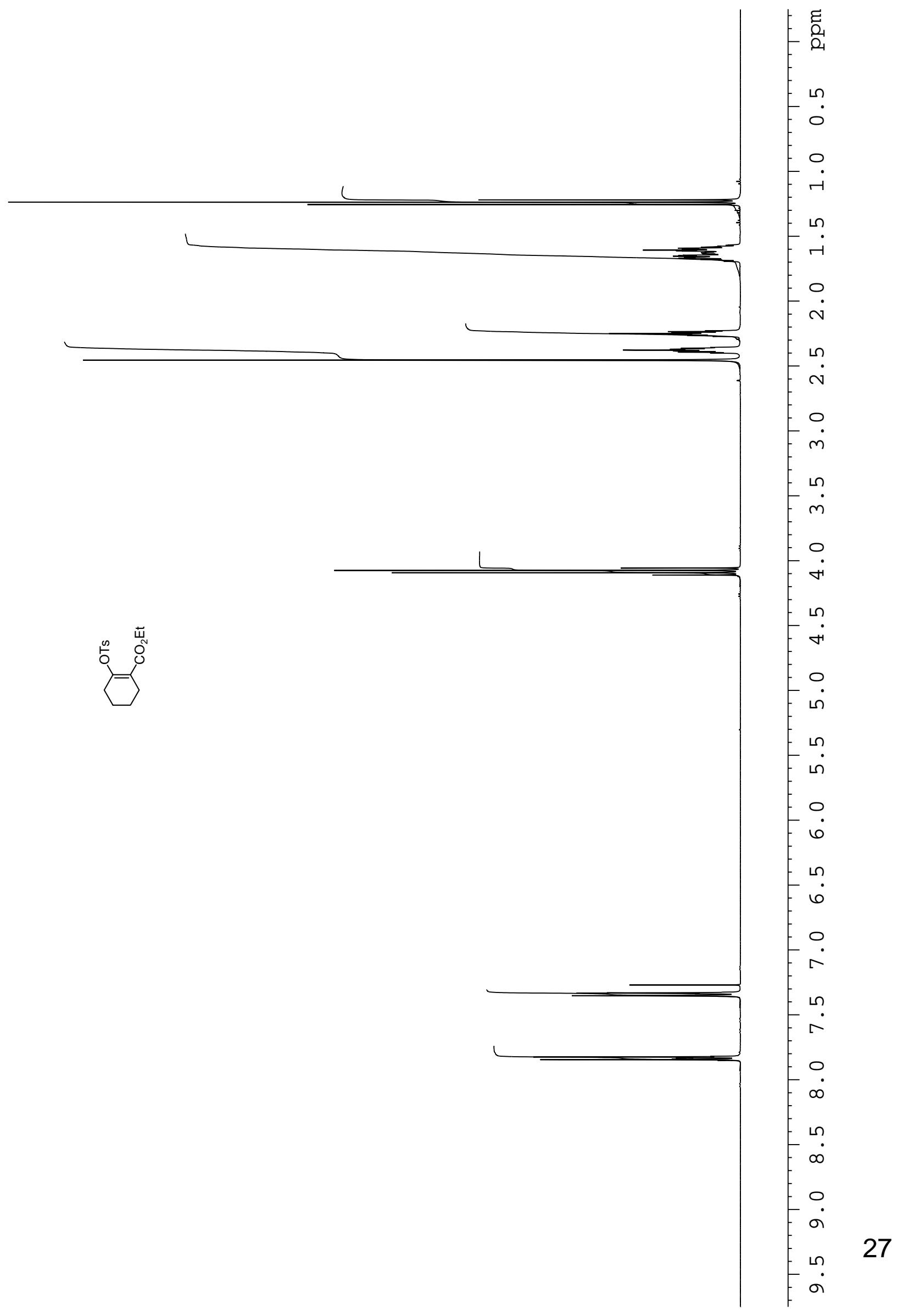



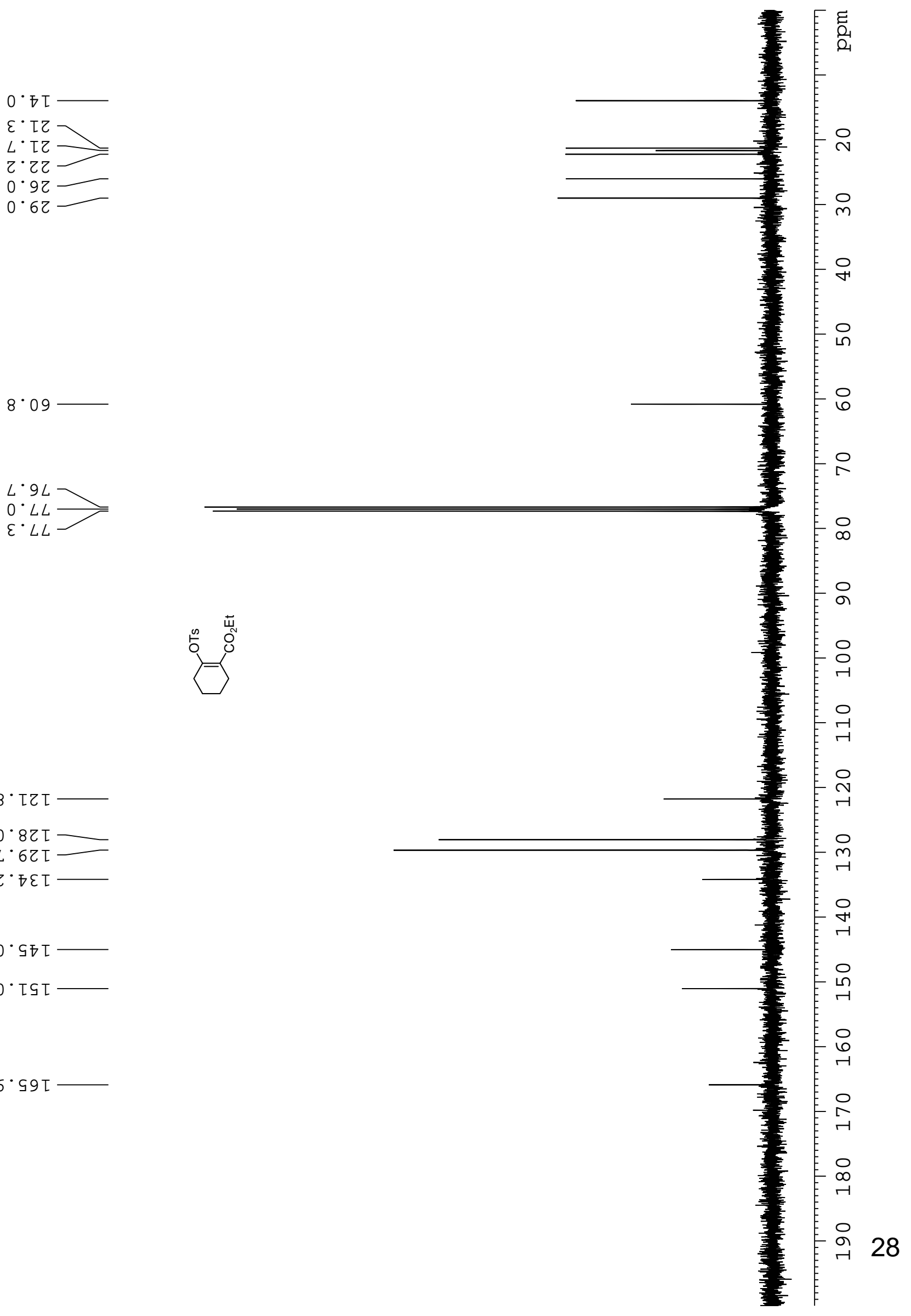


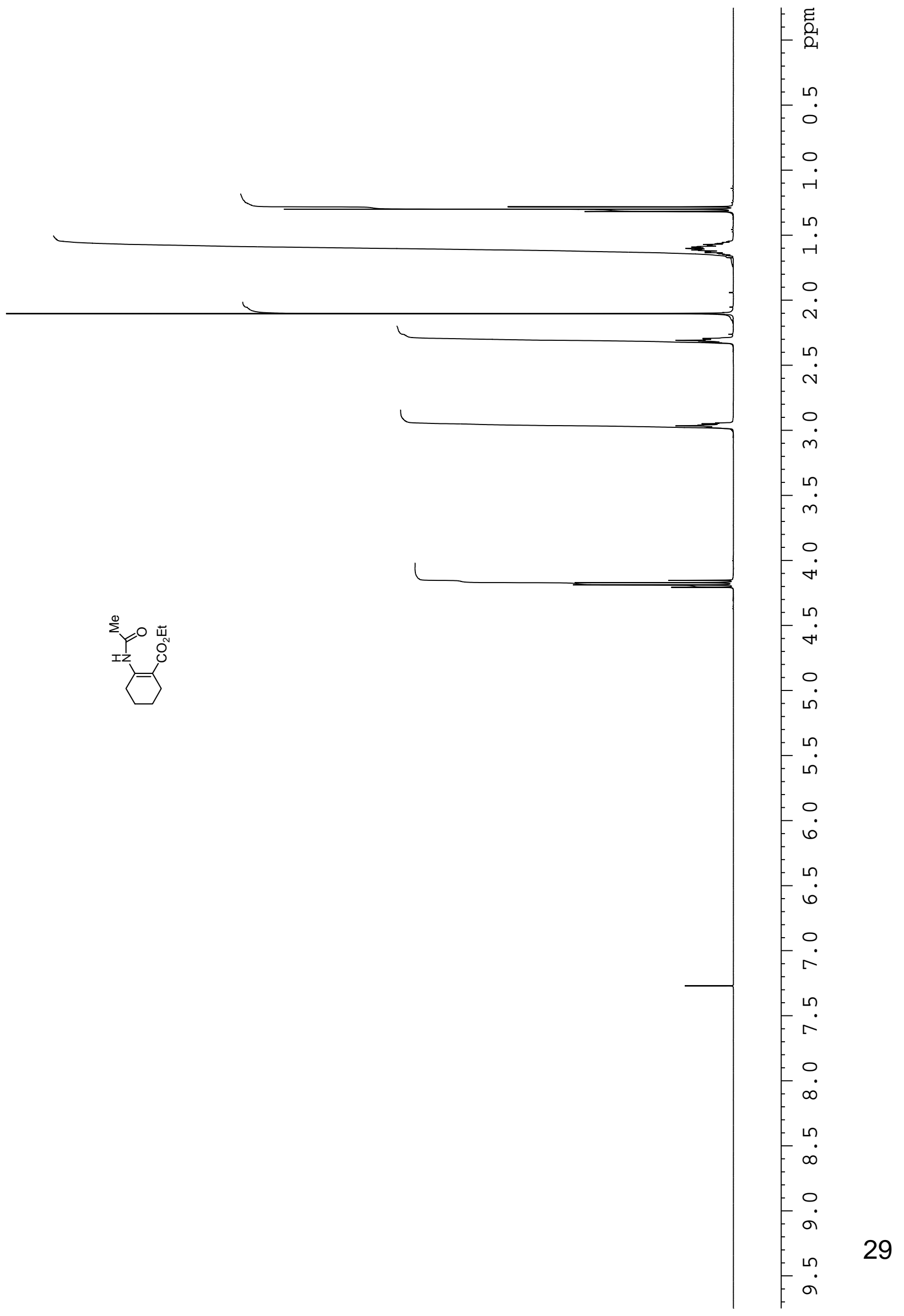




$$
11
$$




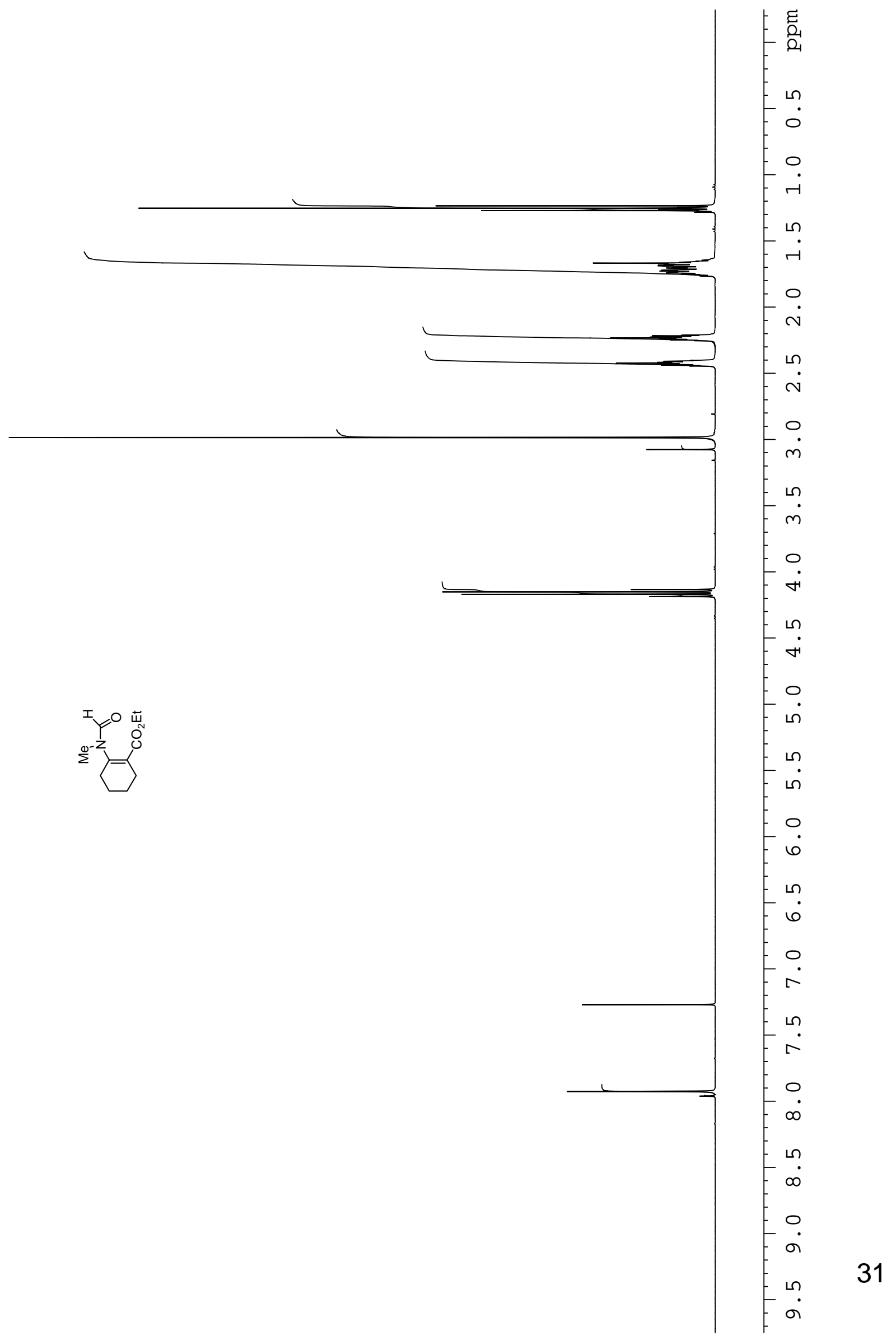



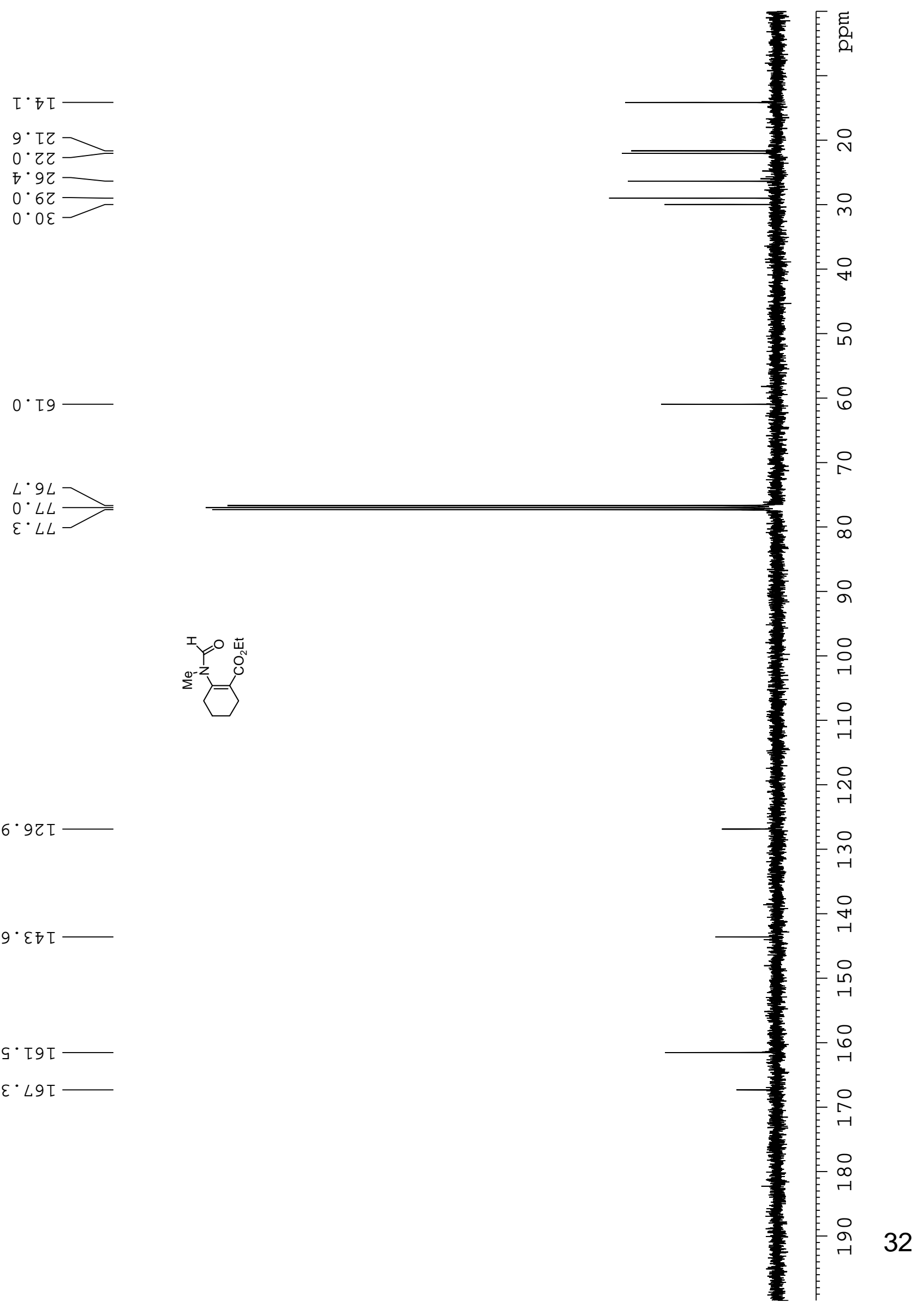


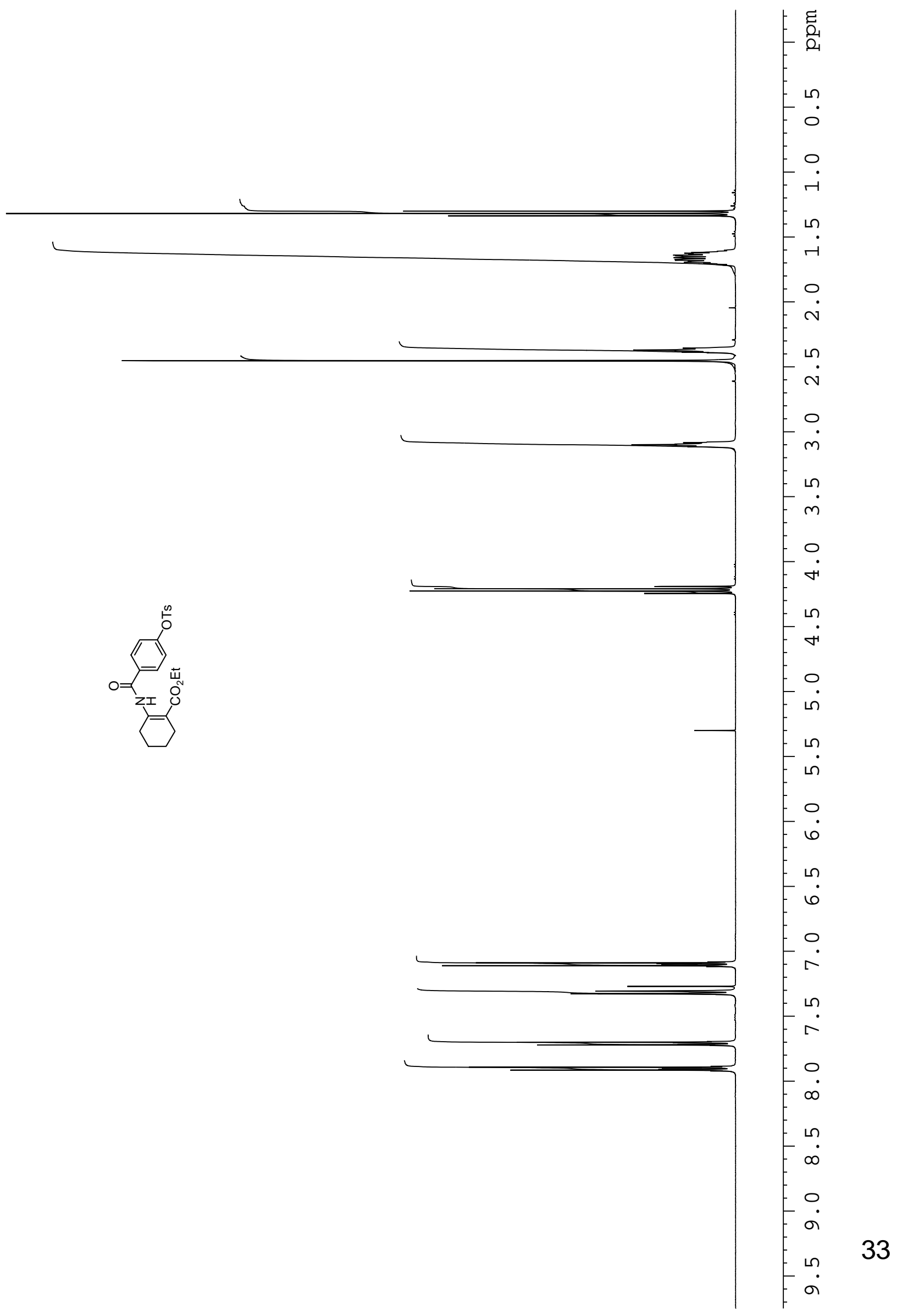


$Z^{\bullet} \nabla \tau$

$L \cdot \tau Z$

$L \cdot \tau Z \longrightarrow$

$6^{\circ} \mathrm{LZ}$

$\varepsilon \cdot \nabla z$

$L \cdot 8 Z$

s.09

$L \cdot 9 L$

$0 \cdot L L \longrightarrow$
$\varepsilon \cdot L$

$8 \cdot 90 t$

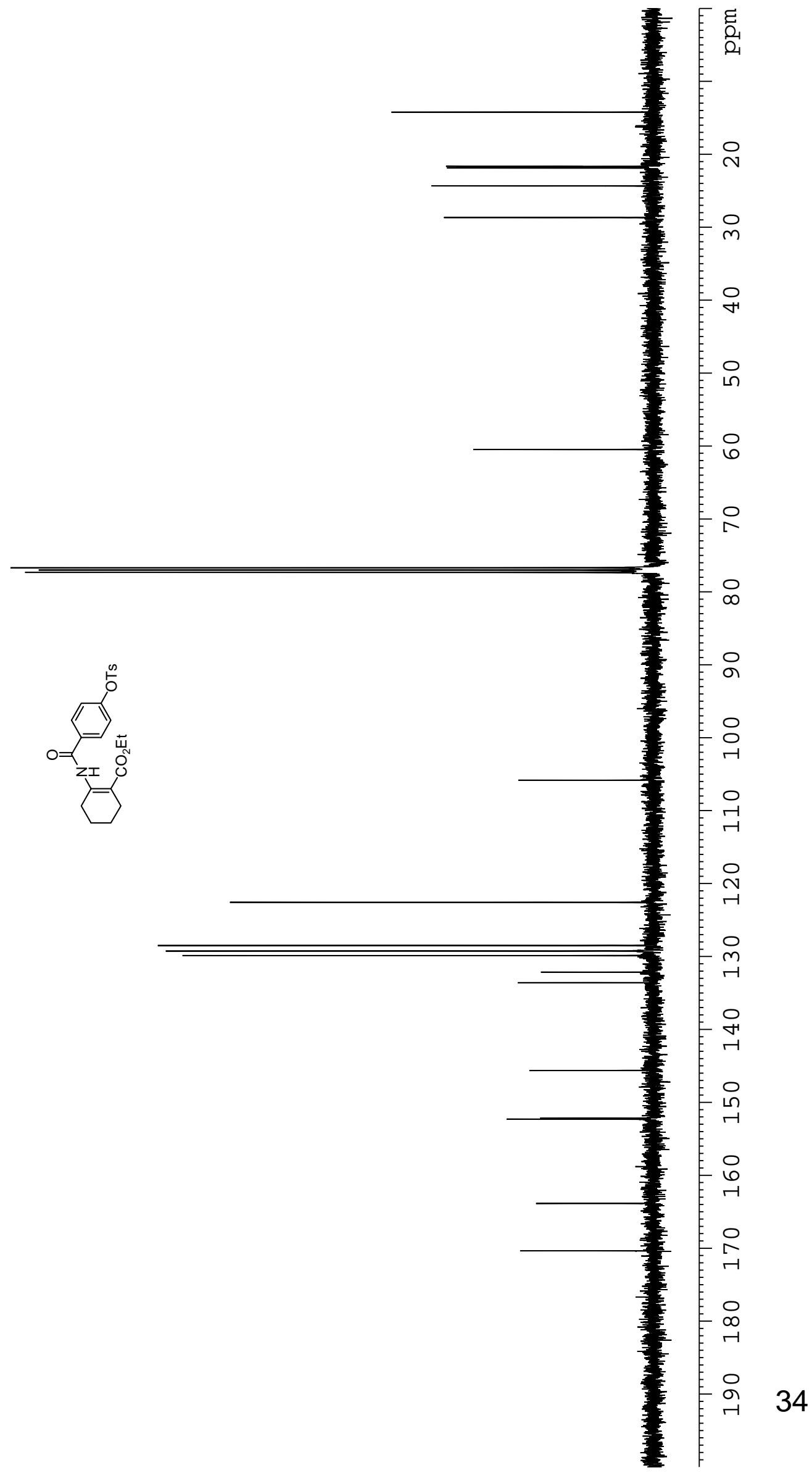

$9^{\circ}$ てて -

$\mathrm{s} \cdot 8 \mathrm{ZI}$

$2 \cdot 6 Z I$

$6 \cdot 6 Z \mathrm{I}$

$\tau \cdot z \varepsilon \tau$

$9 \cdot \varepsilon \varepsilon \tau$

$9 \cdot 9 \nabla L$

$\tau \cdot 2 s I$

$\varepsilon \cdot Z S I$

$6 \cdot \varepsilon 9 I$

$\bar{D} \cdot 0 L \tau$ 